\title{
MiR-146b-5p overexpression attenuates stemness and radioresistance of glioma stem cells by targeting HuR/lincRNA- p21/ $\beta$-catenin pathway
}

\author{
Wei Yang ${ }^{1}$, Hongquan Yu ${ }^{2}$, Yueming Shen ${ }^{1}$, Yingying Liu ${ }^{1}$, Zhanshan Yang ${ }^{1}$, \\ Ting Sun ${ }^{3}$ \\ ${ }^{1}$ School of Radiological Medicine and Protection, Medical College of Soochow University, Collaborative Innovation Center of \\ Radiation Medicine of Jiangsu Higher Education Institutions, Soochow University, Suzhou, Jiangsu 215123, China \\ ${ }^{2}$ Department of Neurosurgery of The First Affiliated Hospital of Jilin University, Changchun, Jilin 130021, China \\ ${ }^{3}$ Neurosurgery and Brain and Nerve Research Laboratory, The First Affiliated Hospital of Soochow University, Suzhou, Jiangsu \\ 215006, China \\ Correspondence to: Wei Yang, e-mail: detachedy@aliyun.com \\ Ting Sun, e-mail: sunting1979st@aliyun.com \\ Keywords: microRNA-146b-5p, glioma stem cells, lincRNA-p2 1, HUR, $\beta$-catenin \\ Received: December 17, $2015 \quad$ Accepted: April 18, $2016 \quad$ Published: May 06, 2016
}

\section{ABSTRACT}

A stem-like subpopulation existed in GBM cells, called glioma stem cells (GSCs), might contribute to cancer invasion, angiogenesis, immune evasion, and therapeutic resistance, providing a rationale to eliminate GSCs population and their supporting niche for successful GBM treatment. LincRNA-p21, a novel regulator of cell proliferation, apoptosis and DNA damage response, is found to be downregulated in several types of tumor. However, little is known about the role of lincRNA-p21 in stemness and radioresistance of GSCs and its regulating mechanisms. In this study, we found that lincRNA-p21 negatively regulated the expression and activity of $\beta$-catenin in GSCs. Downregulation of lincRNA-p21 in GSCs was resulted from upregulation of Hu antigen $R$ (HuR) expression caused by miR-146b-5p downregulation. MiR-146b$5 p$ overexpression increased apoptosis and radiosensitivity, decreased cell viability, neurosphere formation capacity and stem cell marker expression, and induced differentiation in GSCs. Moreover, knock-down lincRNA-p21 or HuR and $\beta$-catenin overexpression could rescue the phenotypic changes resulted from miR-146b-5p overexpression in GSCs. These findings suggest that targeting the $\mathrm{miR}-146 \mathrm{~b}-5 \mathrm{p} / \mathrm{HuR} /$ lincRNA-p21/ $\beta$-catenin signaling pathway may be valuable therapeutic strategies against glioma.

\section{INTRODUCTION}

A growing body of evidence suggest that a stemlike subpopulation existed in glioblastoma multiforme (GBM) cells, named glioma stem cells (GSCs), should be responsible for tumor growth, resistance to therapy and recurrence [1-4]. GSCs represent notable similarities to normal neural stem cells, such as the self-renew capacity, stem cell markers (Sox2 and Nestin) expression and differentiation potential $[5,6]$. GSCs grow like nonadherent spheres in serum-free medium and showed potent tumor formation ability in immuno-compromised mice [7]. Furthermore, they contribute to cancer invasion, angiogenesis, immune evasion, and therapeutic resistance, providing a rationale to eliminate GSCs population and their supporting niche for successful GBM treatment [811]. Elucidation of the molecular mechanisms underlying the therapeutic resistance of GSCs is a critical step to identify novel targets of therapeutic intervention.

Long intergenic non-coding RNAs (lincRNAs) function as transcription and post-transcription regulator governing mRNA splicing, translation and degradation $[12,13]$. Emerging evidence suggests that lincRNA-p21, about $3.0 \mathrm{~kb}$ in length and located nearly $15 \mathrm{~kb}$ upstream of p21/Cdkn1a gene, is a new regulator of cell cycle, apoptosis and DNA repair, and plays a vital role in some diseases including cancer [14-17]. As a p53-induced lincRNA, lincRNA-p21 employs the heterogeneous 
nuclear ribonucleoprotein $\mathrm{K}$ (hnRNP-K) protein to oppress transcription of p53 target gene [18]. Since lincRNA-p21 is downregulated in some kinds of cancer, it might serve as a tumor suppressor [19-21]. Nevertheless, we know little about the pathological function of lincRNA-p21 in glioma cells and GSCs.

It was reported that lincRNA-p21 negatively regulated $\beta$-catenin translation at the post-transcriptional level in HeLa cells [22]. Wnt/ $\beta$-catenin pathway contributes to glioma cells and GSCs proliferation $[23,24]$. Chen et al. reported that glioma stem cell-like phenotype was associated with $\mathrm{Wnt} / \beta$-catenin signal activation [25]. Recently, wang et al. demonstrated that lincRNA-p21 increased colorectal cancer radiosensitivity through deactivating $\beta$-catenin pathway [19]. However, whether lincRNA-p21 could inhibit Wnt/ $\beta$-catenin pathway and function as an radiosensitizer in glioma cells and GSCs remains unknown.

In this study, we investigated the function of lincRNA-p21 in stemness and radioresistance of GSCs and its regulating mechanisms. Our data indicated that lincRNA-p21 was downregulated, while $\beta$-catenin was upregulated in GBM and GSCs cell lines and GBM tumor tissues. LincRNA-p21 could negatively regulate $\beta$-catenin expression and activity in GBM, particularly in GSCs. Downregulation of lincRNA-p21 in GSCs was resulted from upregulation of $\mathrm{Hu}$ antigen $\mathrm{R}$ (HuR) expression caused by miR-146b-5p downregulation. MiR-146b-5p overexpression attenuates stemness and radioresistance of GSCs by targeting HuR/lincRNA-p21/ $\beta$-catenin pathway. Moreover, knock-down lincRNA-p21 or HuR and $\beta$-catenin overexpression could rescue the decreased stemness and radioresistance resulted from miR-146b-5p overexpression in GSCs.

\section{RESULTS}

\section{LincRNA-p21 level is low in GBM}

First we compared lincRNA-p21 level among normal human astrocytes, GBM and GSCs cell lines to study the possible role of lincRNA-p21 in GBM. The results showed that lincRNA-p21 expression in GBM and GSCs cell lines were lower than normal astrocytes cell line NHA. In addition, lincRNA-p21 expression in GSCs were lower than GBM cell lines (Figure 1A). Then, we compared lincRNA-p21 expression in 37 glioma tissues, including 9 low grade astrocytomas (LGA, Grade II), 16 anaplastic astrocytomas (AA, Grade III) and 12 glioblastoma multiforme (GBM, Grade IV), with 8 normal brain tissues. Our results showed that lincRNA-p21 level in glioma tissues was declined compared to normal brain. In addition, lincRNA-p21 level decreased with the grade of glioma (Figure 1B). Our data indicat that lincRNA-p21 is downregulated in GBM, which might play an important role in GBM initiation and resistance to therapy.

\section{$\beta$-catenin is upregulated in GBM and GSCs cell lines and GBM tumor tissues}

It has been reported that lincRNA-p21 inhibited $\beta$-catenin translation in cervical cancer cells [22]. Nonetheless, whether lincRNA-p21 could regulate $\beta$-catenin expression in GBM still needs to be identified. We first examined $\beta$-catenin level in GBM and GSCs cells as well as normal human astrocytes. The results demonstrated that $\beta$-catenin expression was higher in GSCs, at mRNA and protein level, than GBM and NHA cells. In addition, $\beta$-catenin expression in GBM cell lines was higher than NHA cells (Figure 1A and 1D). Consistently, $\beta$-catenin mRNA and protein levels of GBM tissues were higher than normal brain (Figure 1C and 1D). Then, we investigated $\mathrm{Wnt} / \beta$-catenin signal activity in these cell lines through detecting c-myc and cyclin D1 levels, which are the targets of $\beta$-catenin. Our results showed that their mRNA and protein levels were enhanced in GBM and GSCs cells compared to NHA cells (Figure $1 \mathrm{~A}$ and $1 \mathrm{D})$. Wnt/ $\beta$-catenin signal activity was also detected in GBM tissues and normal brain. We mixed the total RNA of 12 GBM and 8 normal brain tissues, respectively. The qRT-PCR results demonstrated that c-myc and cyclin D1 mRNA levels in GBM tissues were higher than normal brain (Figure 1C). Consistently, their protein levels were elevated in GBM tissues compared to normal brain (Figure 1D). Our data showed that lincRNA-p21 and $\beta$-catenin levels in GBM cells and tissues were inversely correlated, which suggested that lincRNA-p 21 might negatively regulate $\beta$-catenin signal activity in GBM cells, particularly in GSCs.

\section{LincRNA-p21 overexpression suppressed Wnt/ק- catenin signal activity in GSCs}

We hypothesized that lincRNA-p21 overexpression might suppress Wnt/ $\beta$-catenin signaling activity in GSCs, so the lincRNA-p21 overexpression recombinant vectors were constructed and were transfected into GSCs to detect its effect. The results showed that lincRNA-p21 overexpression in GSCs decreased $\mathrm{Wnt} / \beta$-catenin signaling activity, as proved by downregulation of $\beta$-catenin targets (Figure 2A and 2B).

\section{Regulation mechanisms of lincRNA-p21 expression}

To explore the possible mechanisms involved in the lincRNA-p21 downregulation in GSCs, first we examined the transcriptional regulation of lincRNA-p21 in GSCs and non-GSCs glioma cells. LincRNA-p21 is transcriptionally regulated by $\mathrm{p} 53$ binding to the p53-binding motif (GGACATGCCCGGGCATGTC) in its promoter [18], so we hypothesized that the interaction between $\mathrm{p} 53$ and lincRNA-p21 might be different in GSCs and nonGSCs glioma cells. To test this, we performed chromatin 
immunoprecipitation analysis to determine whether the binding efficiency of p53 to lincRNA-p21 promoter was different between GSCs and non-GSCs glioma cells. As shown in Figure 3A, the binding efficiency was similar between GSCs and non-GSCs glioma cells, which suggested that downregulation of lincRNA-p21 in GSCs might not result from the transcriptional regulation by $\mathrm{p} 53$. In addition to transcriptional regulation, lincRNA-p21 is also subject to post-transcriptional regulation. It is well documented that lincRNA-p21 levels are regulated by the cooperation of mRNA-binding protein HuR, let-7b and Ago2 protein [22]. We next compared HuR and let$7 \mathrm{~b}$ expression levels in GSCs with non-GSCs glioma cells. As shown in Figure 3B and 3C, non-GSCs glioma cells displayed significantly lower HuR protein levels than GSCs, while let-7b level showed no significant change between GSCs and non-GSCs glioma cells, which suggested that downregulation of lincRNA-p21 in GSCs might result from upregulation of HuR expression. It was reported that $\mathrm{HuR}$ is activated through the $\mathrm{PI} 3 \mathrm{~K} / \mathrm{AKT} /$ $\mathrm{NF}-\kappa \mathrm{B}$ pathway in gastric cancers and through the mTOR/ HSF1 pathway in breast cancer cells [26, 27]. Therefore, we next examined whether elevation of HuR levels was associated with transcriptional activation of the gene through the PI3K/AKT pathway. The level of HuR and $\mathrm{P}-\mathrm{AKT}$ in both GSCs and non-GSCs glioma cells were

A
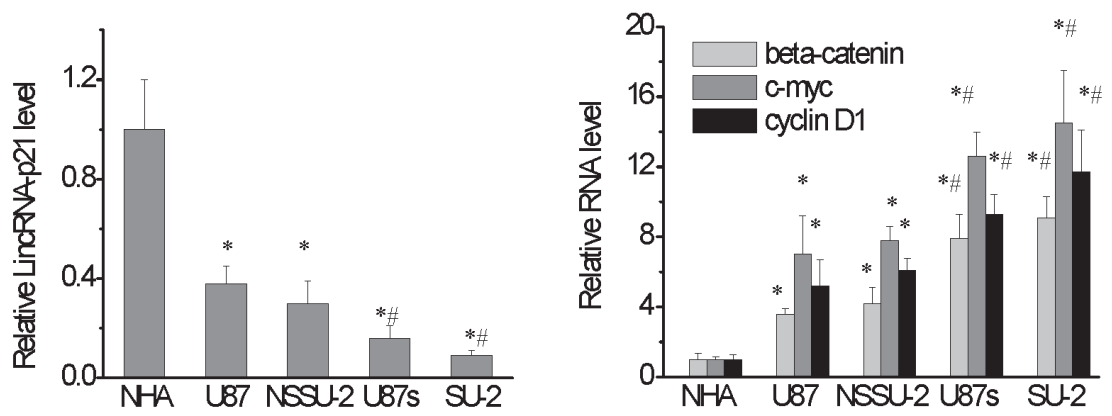

B

C
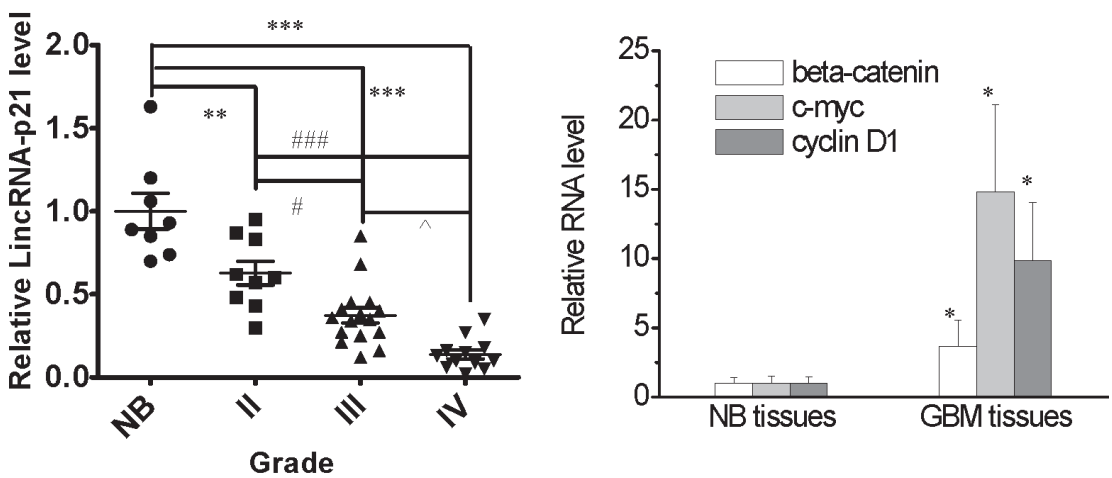

D

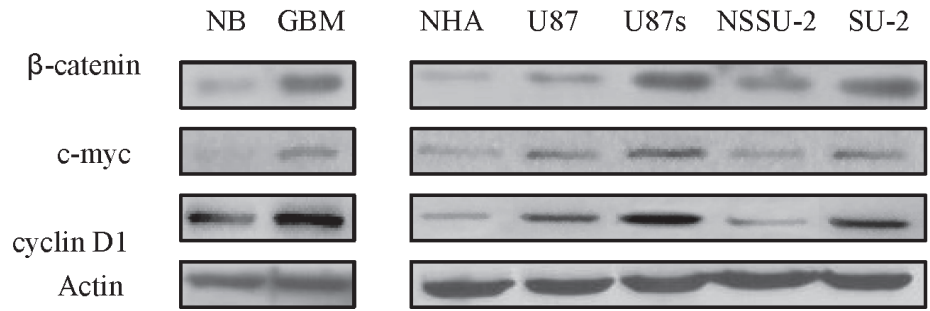

Figure 1: LincRNA-p21 expression level and Wnt/ $\beta$-catenin signaling pathway activity in GBM and GSCs cell lines and GBM tissues. A. Real-time RT-PCR analysis of lincRNA-p21, $\beta$-catenin and its target genes expression levels in GBM and GSCs cell lines. ${ }^{*} P<0.01$ vs NHA, ${ }^{*} P<0.01$ vs U87 or NSSU-2. B. LincRNA-p21 expression level in glioma tissues and normal brain tissues.

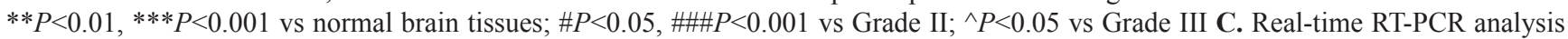
of $\beta$-catenin and its target genes expression levels in GBM tissues and adjacent normal brain tissues. ${ }^{*} P<0.01$ vs normal brain tissues. $\mathbf{D}$. Detection of protein expression of $\beta$-catenin and its target genes in GBM and GSCs cell lines and GBM tissues by Western blot. 
markedly reduced by the PI3K inhibitor LY294002 (Figure 3D). Furthermore, the mRNA and the protein level of HuR were markedly reduced in both GSCs and non-GSCs glioma cells after AKT and mTOR-siRNA transfection (Figure $3 \mathrm{E}$ and $3 \mathrm{~F}$ ). The results demonstrated that HuR is activated through the $\mathrm{PI} 3 \mathrm{~K} / \mathrm{AKT} / \mathrm{mTOR}$ pathway in both GSCs and non-GSCs glioma cells, which suggested that elevation of HuR levels in GSCs compared to nonGSCs glioma cells might be not due to transcriptional regulation. In addition to transcriptional regulation, HuR is also subject to post-transcriptional regulation, which occurs chiefly via microRNAs (miRs) and is poorly studied in glioma cells [28-30]. Human HuR 3' UTR was bio-informaticly analysised for miRNA seed sequences by "starBase v2.0", which integrates data from five predicted softwares (TargetScan, PicTar, PITA, miRanda/ mirSVR and RNA22) [31, 32]. We first choosed miRs whose expression levels showed significant alterations in GBM samples. Then, we selected the common miRs listed in all softwares of starBase. Based on these standard, we screened out 4 miRs: miR-129-5p, 146b-5p, 152-3p and $193 \mathrm{~b}-3 \mathrm{p}$. To determine potential miRNAs which regulate $\mathrm{HuR}$ expression in GSCs and non-GSCs glioma cells, we first examined the expression level of the above mentioned miRs by real-time PCR. As shown in Figure 4A, endogenous level of miR-146b-5p was remarkablely declined in GSCs compared with non-GSCs glioma cells, however, level of miR-129-5p, 152-3p and 193b$3 p$ showed no obvious change between GSCs and nonGSCs glioma cells. As miRs are believed to inversely control mRNA translation, miR-146b-5p were selected as a candidate miR targeting $\mathrm{HuR}$ and we speculated that the enhanced HuR expression in GSCs might result from the reduced level of miR-146b-5p. In order to identify whether miR-146b-5p targets HuR by binding to its 3' UTR sequence (Figure 4B), we employed luciferase reporter assays. Generally, a declined luminescence indicated that the 3'-UTR was effectively bound and targeted by the miRNA $[33,34]$. As shown in Figure 4C, after miR-146b$5 \mathrm{p}$ oligos were transfected into GSCs with the wild type reporter construct pGL3-Luc-HuR, luciferase activity was significantly decreased compared with scramble oligos transfection, whereas mutations in predicted target site of 3'-UTR of HuR gene abrogated the inhibition by miR$146 b-5 p$ oligos. These results suggested that HuR might be a target gene of miR-146b-5p in GSCs. Collectively, these

A

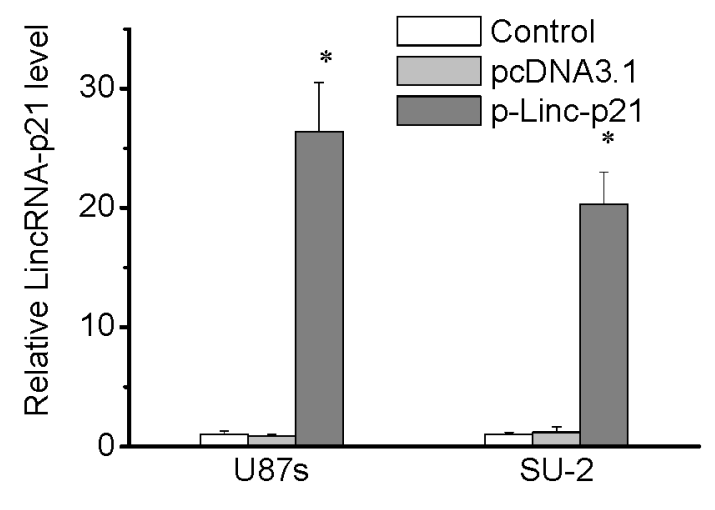

B

pcDNA3.1 p-Linc-p21 pcDNA3.1 p-Linc-p21

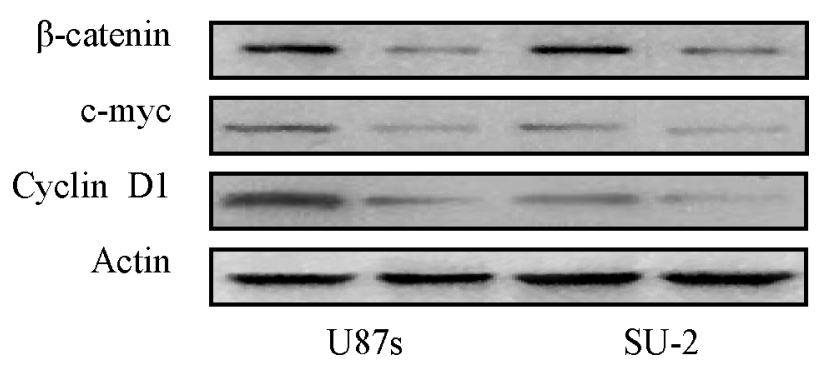

Figure 2: LincRNA-p21 overexpression decreased $\boldsymbol{\beta}$-catenin expression and activity in GSCs. A. Real-time RT-PCR analysis of lincRNA-p21 expression levels in GSCs transfected with lincRNA-p21 overexpression recombinant vectors. ${ }^{*} P<0.01$ vs Control. B. Detection of protein expression of $\beta$-catenin and its target genes in GSCs with lincRNA-p21 overexpression by Western blot. 
data demonstrated that miR-146b-5p was downregulated in GSCs compared to that of non-GSCs glioma cells, which contributed to enhanced HuR expression, resulting in the downregulation of lincRNA-p21 expression, which led to $\mathrm{Wnt} / \beta$-catenin signaling activation in GSCs.

A

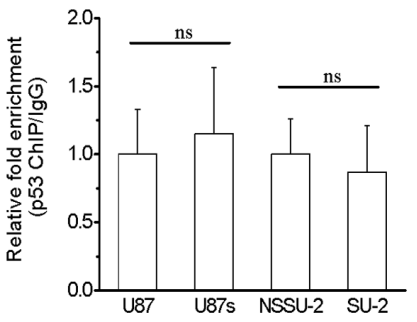

C

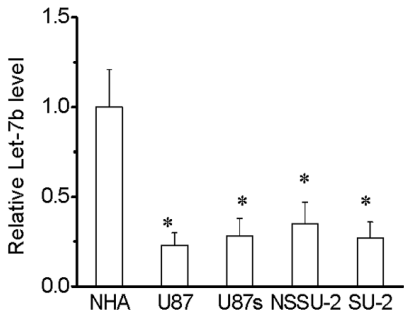

MiR-146b-5p overexpression suppressed Wnt/Bcatenin signaling activity by targeting $\mathrm{HuR} /$ lincRNA-p21 pathway in GSCs

We hypothesized that miR-146b-5p overexpression might suppressed $\beta$-catenin expression and activity in GSCs through targeting HuR/lincRNA-p21 pathway.

B

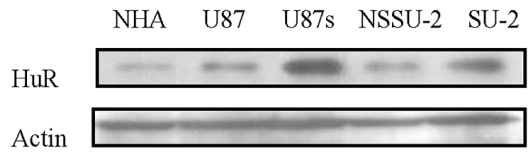

D

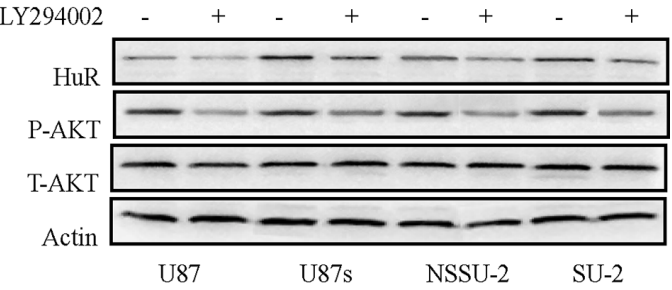

E
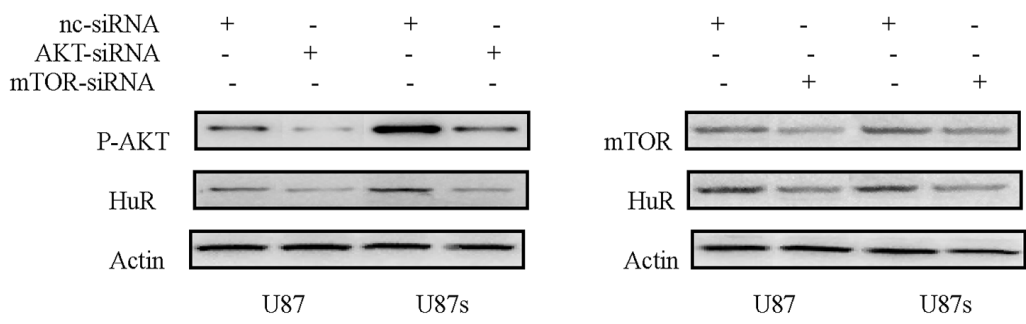

F

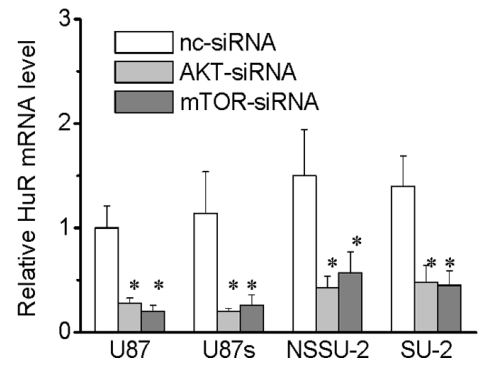

Figure 3: Regulation mechanisms of lincRNA-p21 expression. A. p53 enrichment at the human lincRNA-p21 promoter in GSCs and non-GSCs glioma cells as quantified by Real-time RT-PCR. The binding efficiency of p53 and lincRNA-p21 promoter in GSCs showed no significant difference compared to the corresponding non-GSCs glioma cells. B. Detection of HuR expression levels in GSCs and non-GSCs glioma cells by Western blot. C. Real-time RT-PCR analysis of let-7b expression levels in GSCs and non-GSCs glioma cells. $* P<0.01$ vs NHA. D. Transcriptional activation of HuR through PI3K/AKT pathway in both GSCs and non-GSCs glioma cells. E. HuR protein expression levels were reduced in both GSCs and non-GSCs glioma cells after AKT and mTOR-siRNA transfection. F. Real-time RT-PCR analysis of HuR mRNA levels in both GSCs and non-GSCs glioma cells after AKT and mTOR-siRNA transfection. $* P<0.01$ vs nc-siRNA. 
Lentivirus encoding either miR-146b-5p or scramble sequence were transfected into GSCs to generate stable cell lines. First miR-146b-5p levels in GSCs were detected by real-time PCR. As shown in Figure 5A, miR-146b-5p levels in GSCs with miR-146b-5p integration were higher than control cells, while miR-146b-5p levels in GSCs with scramble sequence integration showed no obvious changes compared with control cells. We next investigated whether miR-146b-5p overexpression could reverse the enhanced HuR expression in GSCs. As shown in Figure 5B, 5C and 5D, miR-146b-5p overexpression markedly reduced HuR expression and decay of HuR target lincRNA-p21 leading to increased lincRNA-p21 expression in GSCs. We further investigated the effect of miR-146b-5p overexpression on $\beta$-catenin signaling activity in GSCs. As shown in Figure 5D, miR-146b-5p overexpression significantly decreased cytoplasmic and nuclear $\beta$-catenin expression as well as $\beta$-catenin targets in GSCs. It was reported that c-myc was an important stem cell regulator [35-37]. Therefore, we further investigated the effect of miR$146 b-5 p$ overexpression on GSCs stemness. As shown in Figure 5D, the stem cell marker Bmil was significantly decreased, while the differentiation marker glial fibrillary acidic protein (GFAP) was significantly increased in GSCs with miR-146b-5p overexpression, which suggested that miR-146b-5p overexpression decreased GSCs stemness. Our results demonstrated that miR-146b-5p overexpression could suppress Wnt/ $\beta$-catenin signaling

A

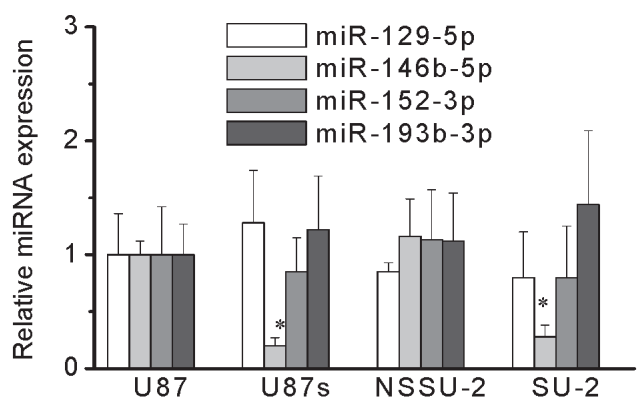

B

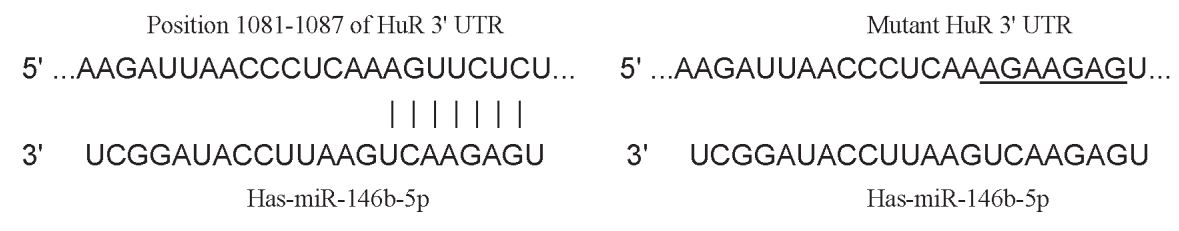

C
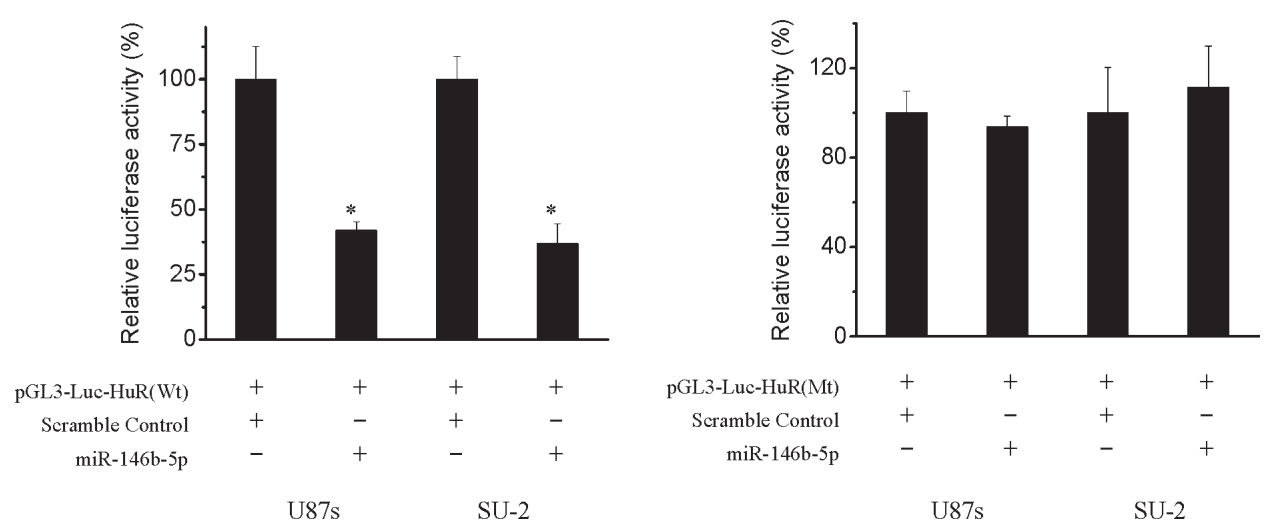

Figure 4: Post-transcriptional regulation of HuR. A. Real-time RT-PCR analysis of the expression levels of the putative miRs that could target HuR. ${ }^{*} P<0.01$ vs U87 cells. B. A putative miR-146b-5p target site in the wild type and mutated 3'UTR of HuR. C. Relative luciferase activity in GSCs transfected with pGL3-Luc vector containing wild type and mutated 3'UTR of HuR. * $P<0.01$ vs cells transfected with scramble oligos. 
activity through targeting HuR/lincRNA-p21 pathway in GSCs.

\section{MiR-146b-5p overexpression reduced GSCs viability and arrested GSCs in G0/G1 phase}

The effect of miR-146b-5p overexpression on GSCs viability was detected using MTT assay. GSCs viability was assayed on 2, 4 and 6 days after GSCs/Lv-miR-146b$5 p$ transfected with $p-H u R, p-\beta$-catenin and lincRNA-p21siRNA. The protein levels of HuR, $\beta$-catenin and c-myc as well as RNA levels of lincRNA-p21 of these cells were

A

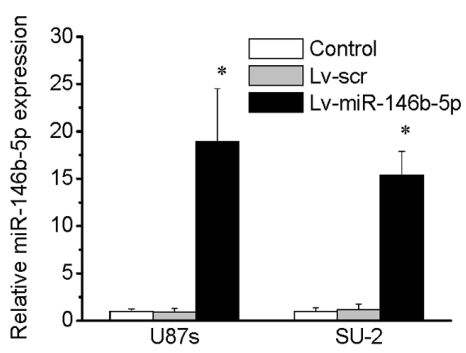

C

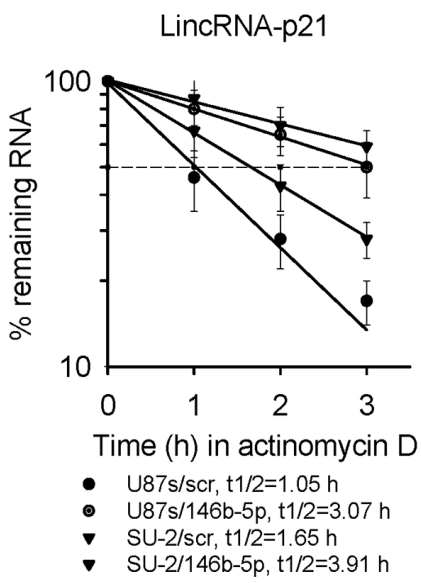

D

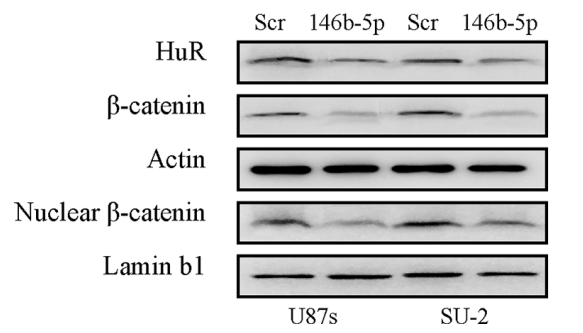

detected 2 days after transfection. C-Myc expression were rescued in GSCs/Lv-miR-146b-5p transfected with p-HuR, p- $\beta$-catenin and lincRNA-p21-siRNA. Both HuR overexpression and lincRNA-p21-siRNA decreased the elevated lincRNA-p21 level in GSCs/Lv-miR-146b-5p (Figure 6A). MiR-146b-5p overexpression decreased U87s and SU-2 cell viability and the lowest viability was $61.8 \%$ and $58.8 \%$ after 6 days culture, respectively (Figure $6 \mathrm{~B} ; P<0.05$ or 0.01 ). Our data demonstrated that miR-146b-5p overexpression decreased viability of GSCs. However, after p-HuR, p- $\beta$-catenin and lincRNA-p21siRNA transfection, cell viability of GSCs/Lv-miR-146b-

\section{B}
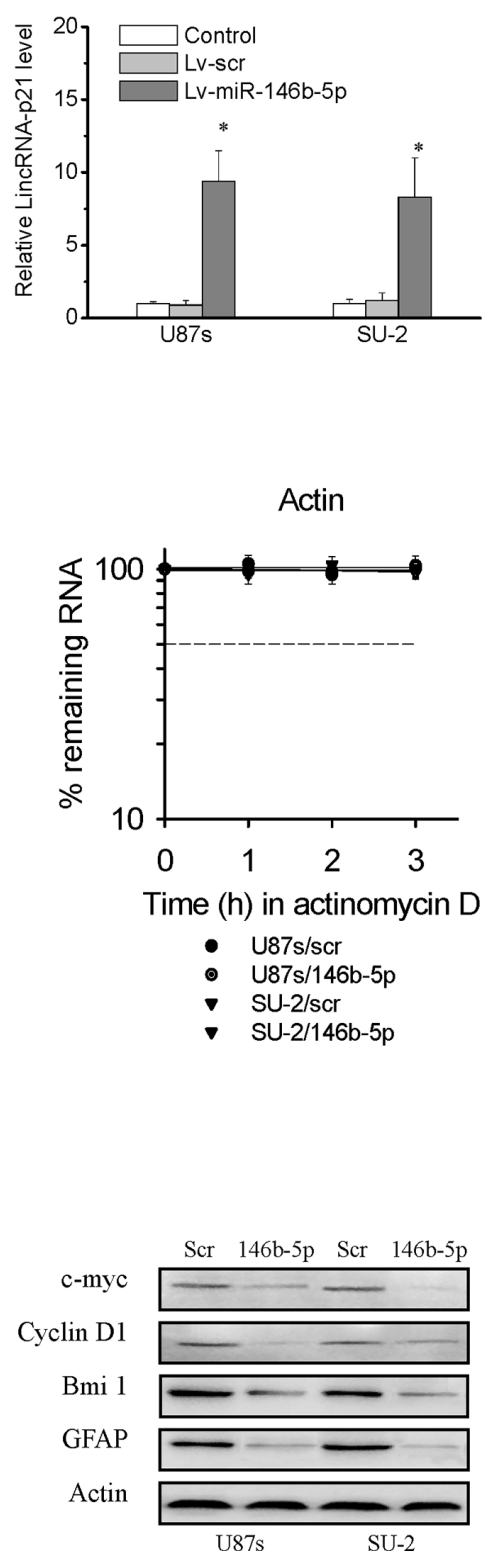

Figure 5: MiR-146b-5p overexpression suppressed Wnt/ß-catenin signaling activity through targeting HuR/ lincRNA-p21 pathway in GSCs. A. Detection of miR-146b-5p expression in GSCs with stable integration of miR-146b-5p by realtime PCR. ${ }^{*} P<0.01$ vs Control. B. Detection of lincRNA-p21 expression in GSCs with miR-146b-5p overexpression by real-time PCR. $* P<0.01$ vs Control. C. LincRNA-p21 had slower decay in GSCs with miR-146b-5p overexpression. D. Detection of protein expression of $\beta$-catenin and its target genes in GSCs with miR-146b-5p overexpression by Western blot. 
$5 p$ showed no significant change compared with GSCs with scramble sequence integration, which suggested that knock-down lincRNA-p21 or HuR and $\beta$-catenin overexpression could rescue cell viability of GSCs with miR-146b-5p overexpression. To study the mechanism of miR-146b-5p mediated inhibition of cell proliferation, we analyzed GSCs cell cycle using flow cytometry. After 2 days culture, more $\mathrm{G} 0 / \mathrm{G} 1$ phase cells and less $\mathrm{S}$ phase cells were found in GSCs/Lv-miR-146b-5p compared to GSCs/Lv-scr (Figure 7A and 7B; $P<0.01$ ). The results showed that miR-146b-5p overexpression arrested GSCs in G0/G1 phase. Nevertheless, the cell cycle arrest induced by miR-146b-5p overexpression also was rescued by HuR and $\beta$-catenin overexpression or lincRNA-p21 knockdown in GSCs.

\section{MiR-146b-5p overexpression increased apoptosis of GSCs}

GSCs apoptosis was detected by flow cytometry $48 \mathrm{~h}$ after $\mathrm{p}-\mathrm{HuR}, \mathrm{p}-\beta$-catenin and lincRNA-p 21 -siRNA transfection. The data indicated that apoptosis of GSCs with miR-146b-5p overexpression was significantly increased compared with GSCs with scramble sequence integration (Figure 8A and 8B). However, after p-HuR, p- $\beta$-catenin and lincRNA-p21-siRNA transfection, apoptotic rate of GSCs/Lv-miR-146b-5p showed no significant change compared with that of GSCs/Lv-scr, which suggested that knock-down lincRNA-p21 or HuR and $\beta$-catenin overexpression could rescue apoptosis of GSCs with miR-146b-5p overexpression.
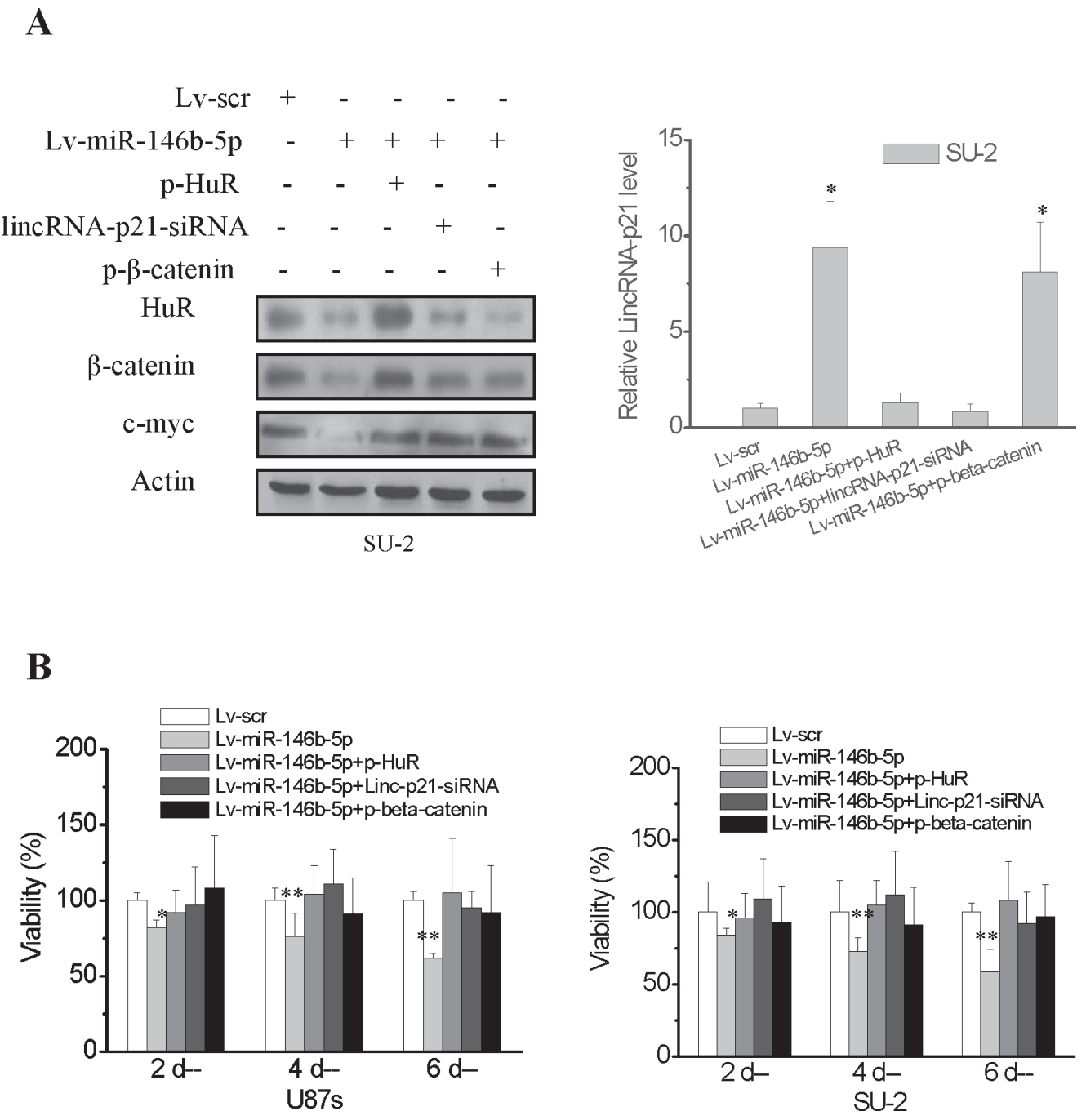

Figure 6: MiR-146b-5p overexpression decreased viability of GSCs. The effect of miR-146b-5p overexpression on cell viability of GSCs was investigated in vitro by MTT assay. Cell viability was detected on 2, 4 and 6 days after GSCs/Lv-miR-146b-5p transfected with p-HuR, p- $\beta$-catenin and lincRNA-p21-siRNA. A. The protein levels of HuR, $\beta$-catenin and c-myc as well as RNA levels of lincRNA-p21 of GSCs/Lv-miR-146b-5p transfected with p-HuR, p- $\beta$-catenin and lincRNA-p21-siRNA were detected 2 days after transfection. $* P<0.01$ vs Lv-scr. B. MiR-146b-5p overexpression decreased GSCs cell viability. ${ }^{*} P<0.05$, ${ }^{*} P<0.01$ vs Lv-scr. 


\section{MiR-146b-5p overexpression reduced GSCs neurosphere formation}

GSCs were seeded into 96-well plates at different density. After $12 \mathrm{~d}$ culture, diameters of GSCs/Lv-miR$146 b-5 p$ neurospheres were reduced compared with those of GSCs/Lv-scr (Figure 9A), and cells forming neurospheres were also reduced (Figure 9B). The results showed that miR-153 overexpression decreased GSCs neurosphere formation. After $\mathrm{p}-\mathrm{HuR}, \mathrm{p}-\beta$-catenin and lincRNA-p21-siRNA transfection, neurosphere diameter and the percentage of cells forming neurospheres of GSCs/
A

Scr

146b-5p

$146 b-5 p+p-H u R$

146b-5p+Linc-

p21-siRNA

Catenin

\section{B}

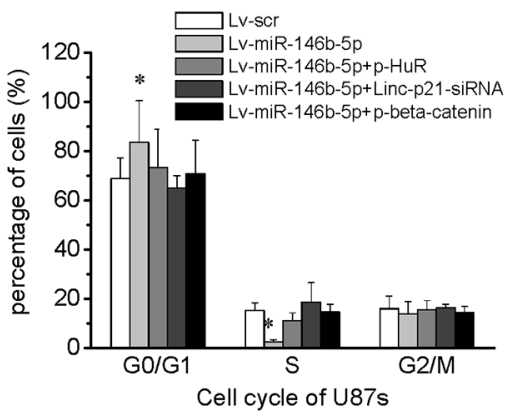

$\mathrm{U} 87 \mathrm{~s}$
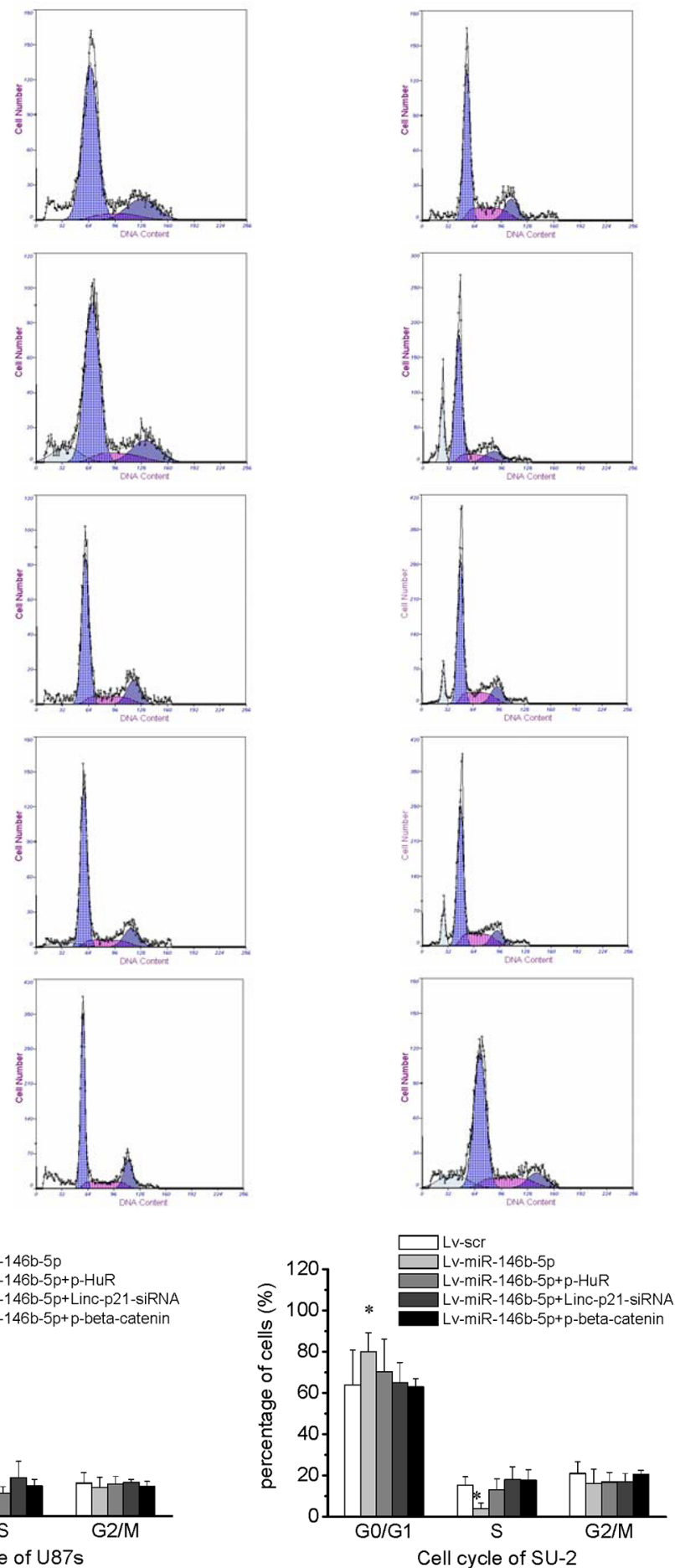

Figure 7: GSCs with miR-146b-5p overexpression arrested in the G0/G1 phase. A. Cell cycle of GSCs analyzed by flow cytometry. B. Cell cycle arrest caused by miR-146b-5p overexpression was rescued by HuR and $\beta$-catenin overexpression or lincRNA-p21 knock-down in GSCs. ${ }^{*} P<0.01$ vs Lv-scr. 
Lv-miR-146b-5p showed no difference compared with that of GSCs/Lv-scr, which suggested that knock-down lincRNA-p21 or HuR and $\beta$-catenin overexpression could rescue the neurosphere formation capacity of GSCs with miR-146b-5p overexpression.

\section{MiR-146b-5p overexpression decreased GSCs stemness and induced differentiation}

Flow cytometry analysis showed that stem cell markers CD133 and nestin expressions in GSCs/Lv-miR-

A

$\operatorname{scr}$

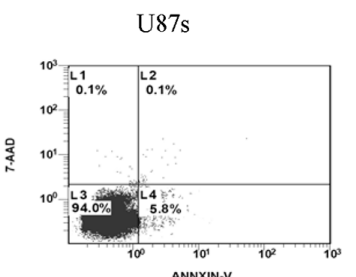

$146 \mathrm{~b}-5 \mathrm{p}$
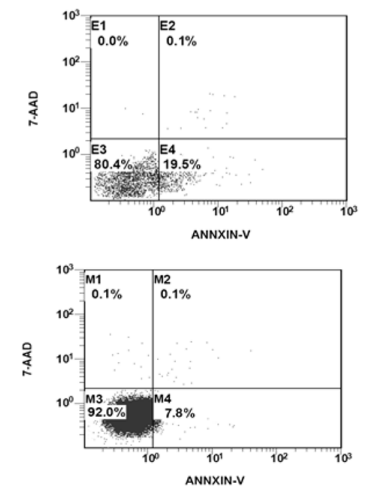

$146 b-5 p+$ Lincp21-siRNA
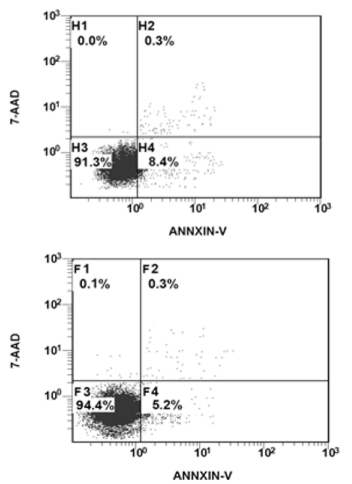

146b-5p significantly decreased $(P<0.01)$ compared with those of GSCs/Lv-scr, while the differentiation marker glial fibrillary acidic protein (GFAP) increased (Figure $10 \mathrm{~A}$ and $10 \mathrm{~B} ; P<0.01)$. GSCs were also stained with immunofluoresent method for CD133, nestin, GFAP and Tuj-1. Representative photomicrographs showed that miR-146b-5p decreased CD133 and nestin expression and increases GFAP and Tuj-1expression (Figure 10C). Our results indicated that miR-146b-5p overexpression decreased GSCs stemness and induced differentiation. After p-HuR, p- $\beta$-catenin and lincRNA-p21-siRNA
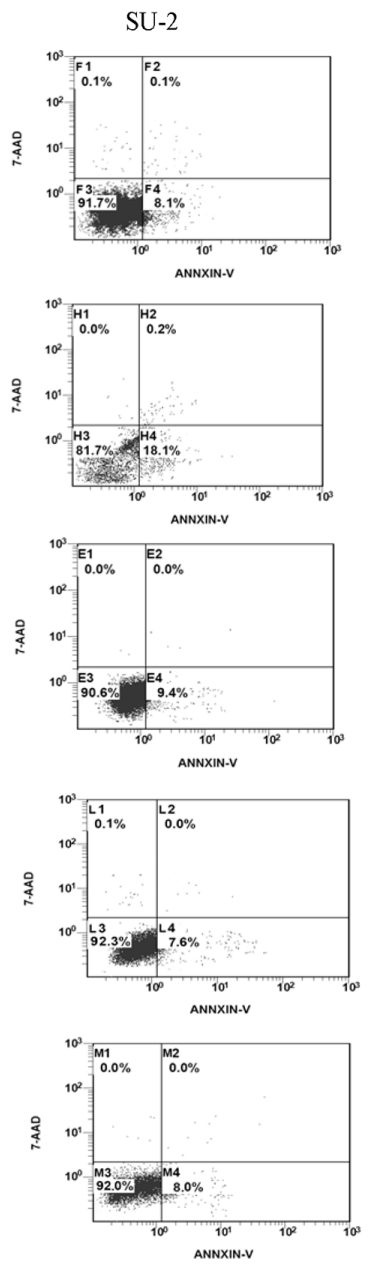

$\mathbf{B}$
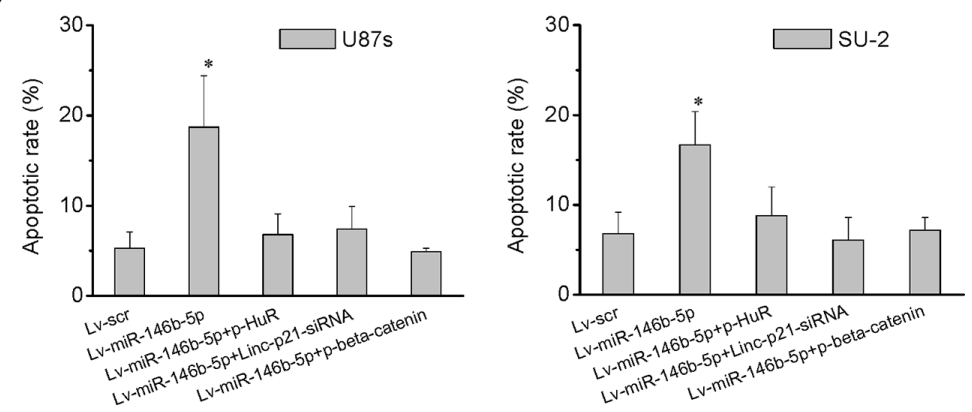

Figure 8: MiR-146b-5p overexpression increased apoptosis of GSCs. A. Apoptosis of GSCs analyzed by flow cytometry. B. Knock-down lincRNA-p21 or HuR and $\beta$-catenin overexpression rescued apoptosis of GSCs with miR-146b-5p overexpression. ${ }^{*} P<0.01$ vs Lv-scr. 
transfection, stem and differentiation markers of GSCs/LvmiR-146b-5p showed no significant difference compared with that of GSCs/Lv-scr, which suggested that knockdown lincRNA-p21 or HuR and $\beta$-catenin overexpression could rescue the induced differentiation of GSCs owing to miR-146b-5p overexpression.

\section{MiR-146b-5p overexpression increased radiosensitivity of GSCs}

After exposed to various dose of X-ray, GSCs survival curves, as shown in Figure 11, were obtained. It is clear that GSCs with miR-146b-5p overexpression were more radiosensitive than GSCs with scramble sequence integration. After p-HuR, p- $\beta$-catenin and lincRNA-p21-
siRNA transfection, radiosensitivity of GSCs/Lv-miR$146 \mathrm{~b}-5 \mathrm{p}$ decreased. These results indicated that knockdown lincRNA-p21 or HuR and $\beta$-catenin overexpression could rescue the decreased radioresistance resulting from miR-146b-5p overexpression in GSCs.

\section{MiR-146b-5p overexpression reduces tumorigenic capacity of GSCs in vivo}

Orthotopic transplantation is a golden standard to determine tumor-initiating capacity of cancer stem cells. To explore the effect of miR-146b-5p overexpression on tumor formation, GSCs stably expressing miR-146b-5p mature sequence or scramble sequence were intracranially implanted into immuno-compromised hosts. Tumor-

A

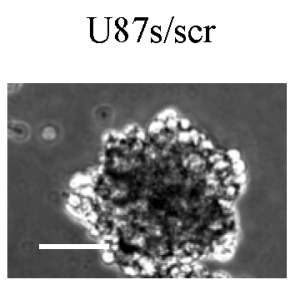

$\mathrm{SU}-2 / \mathrm{scr}$

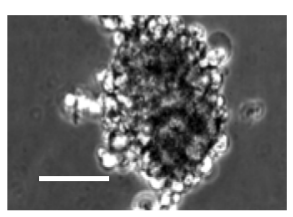

$\mathrm{U} 87 \mathrm{~s} / 146 \mathrm{~b}-5 \mathrm{p}$

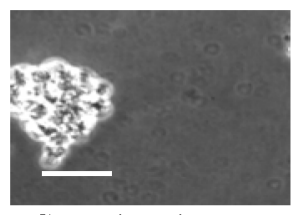

SU-2/146b-5p

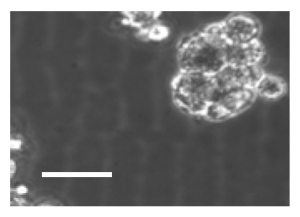

B

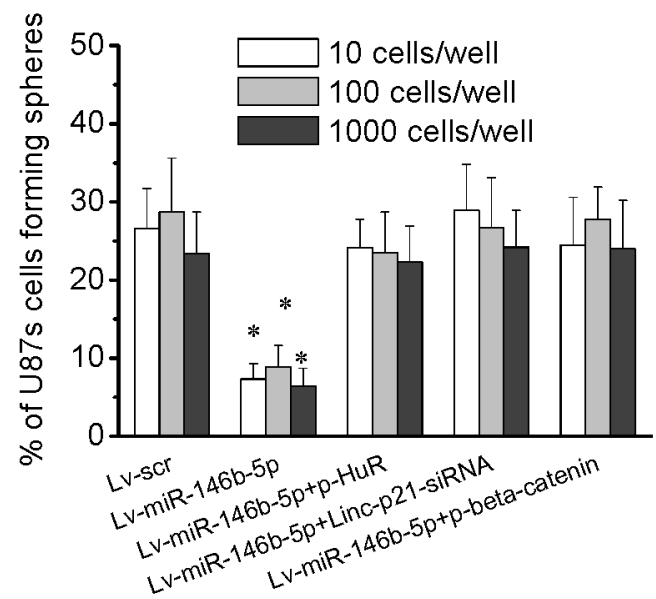

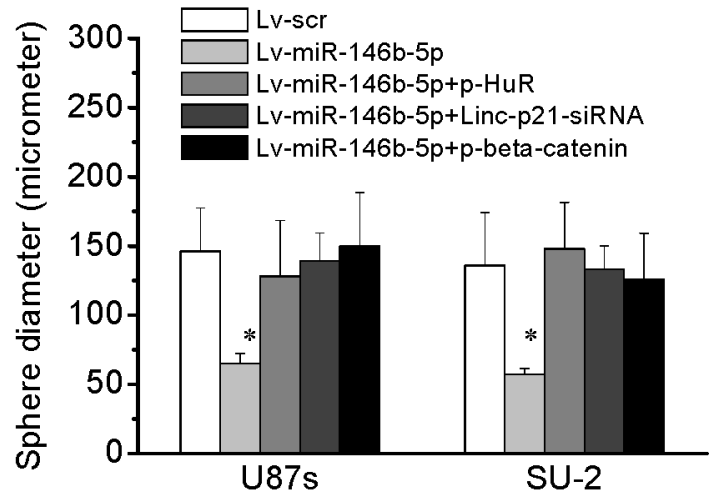

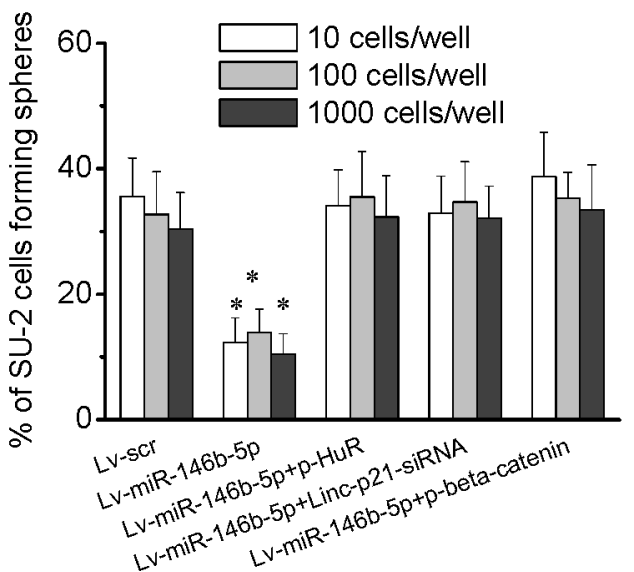

Figure 9: MiR-146b-5p overexpression decreased the neurosphere formation capacity of GSCs. A. The diameters of neurospheres of GSCs with miR-146b-5p overexpression plated at 100 cells per well in 96 -well plates. ${ }^{*} P<0.01 \mathrm{vs} \mathrm{Lv-scr}$. Representative images of neurospheres (light microscope). Scale bar $=50 \mu \mathrm{m}$. B. The percentage of GSCs with miR-146b-5p overexpression forming neurospheres. ${ }^{*} P<0.01$ vs $\mathrm{Lv}$-scr. 
A

\section{CD133}
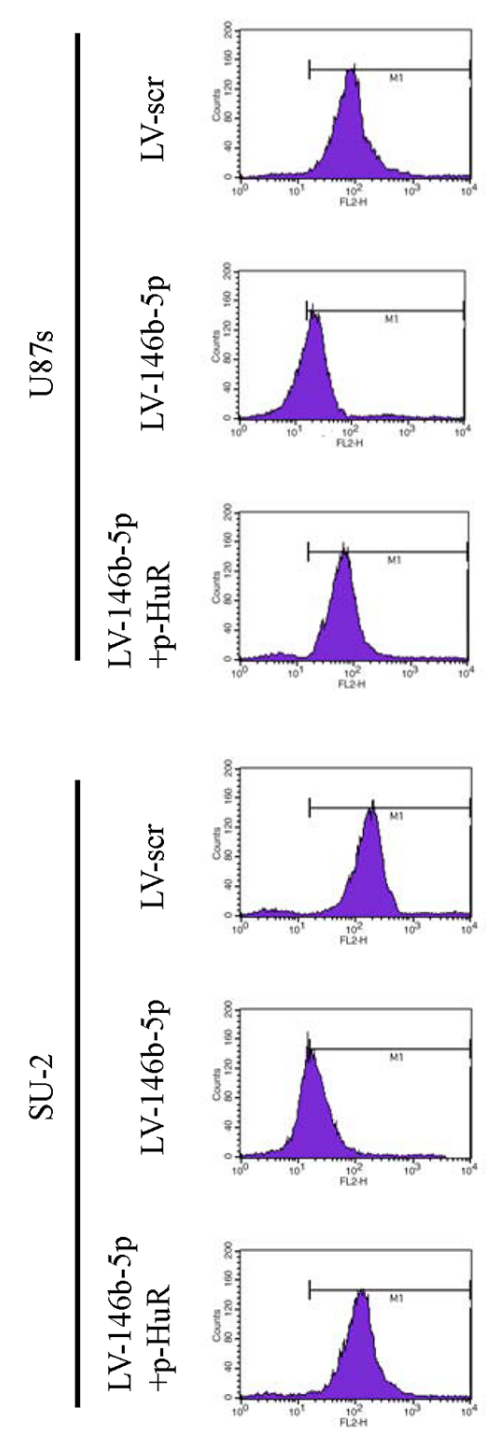

Nestin
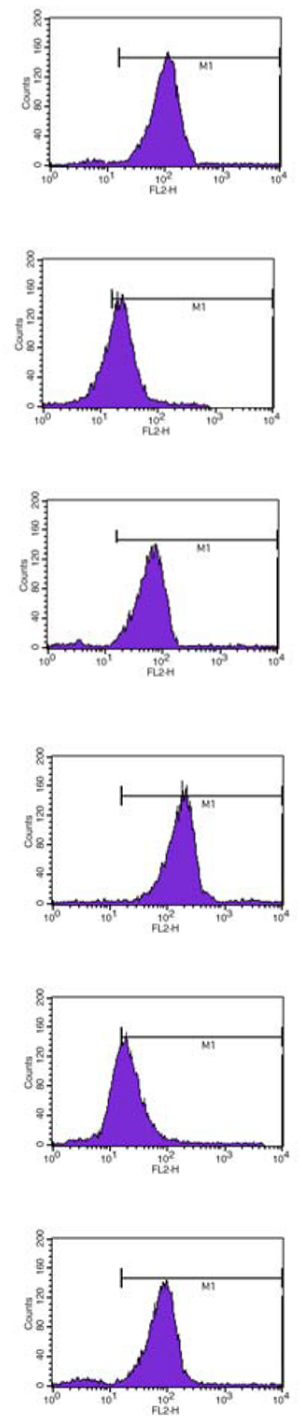

GFAP
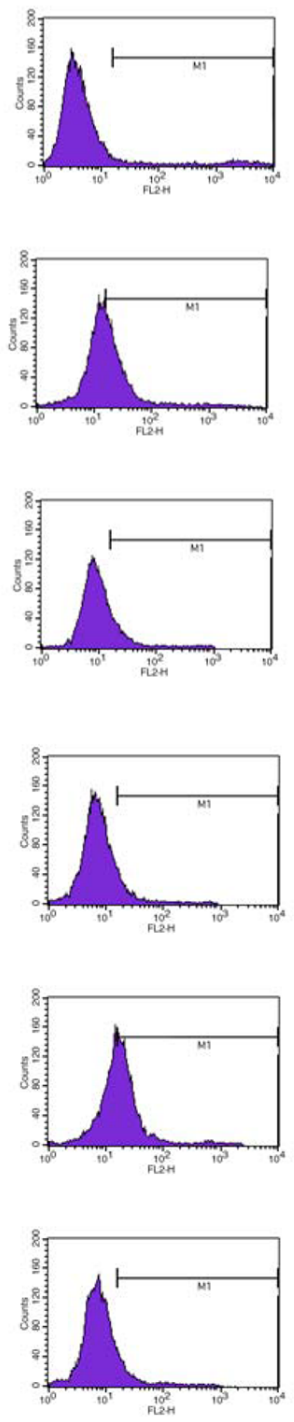
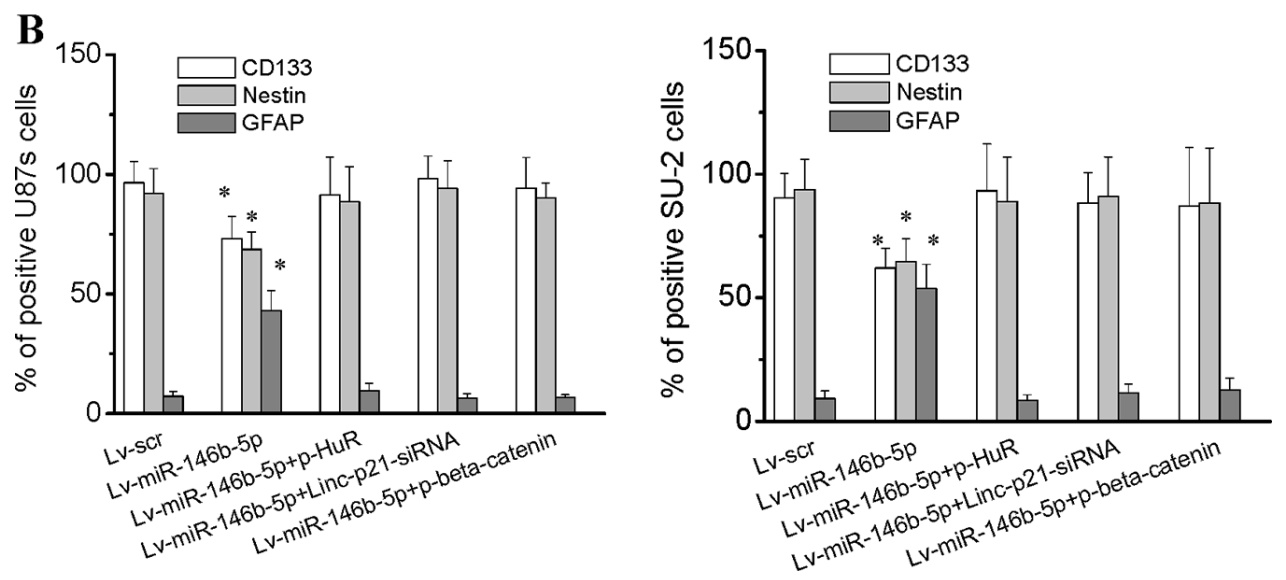

Figure 10: MiR-146b-5p overexpression decreased stemness and induced differentiation in GSCs. A. Flow cytometry analysis of the expression of stem cell markers CD133 and nestin and differentiation marker GFAP. B. The percentage of positive GSCs. $* P<0.01$ vs Lv-scr. 

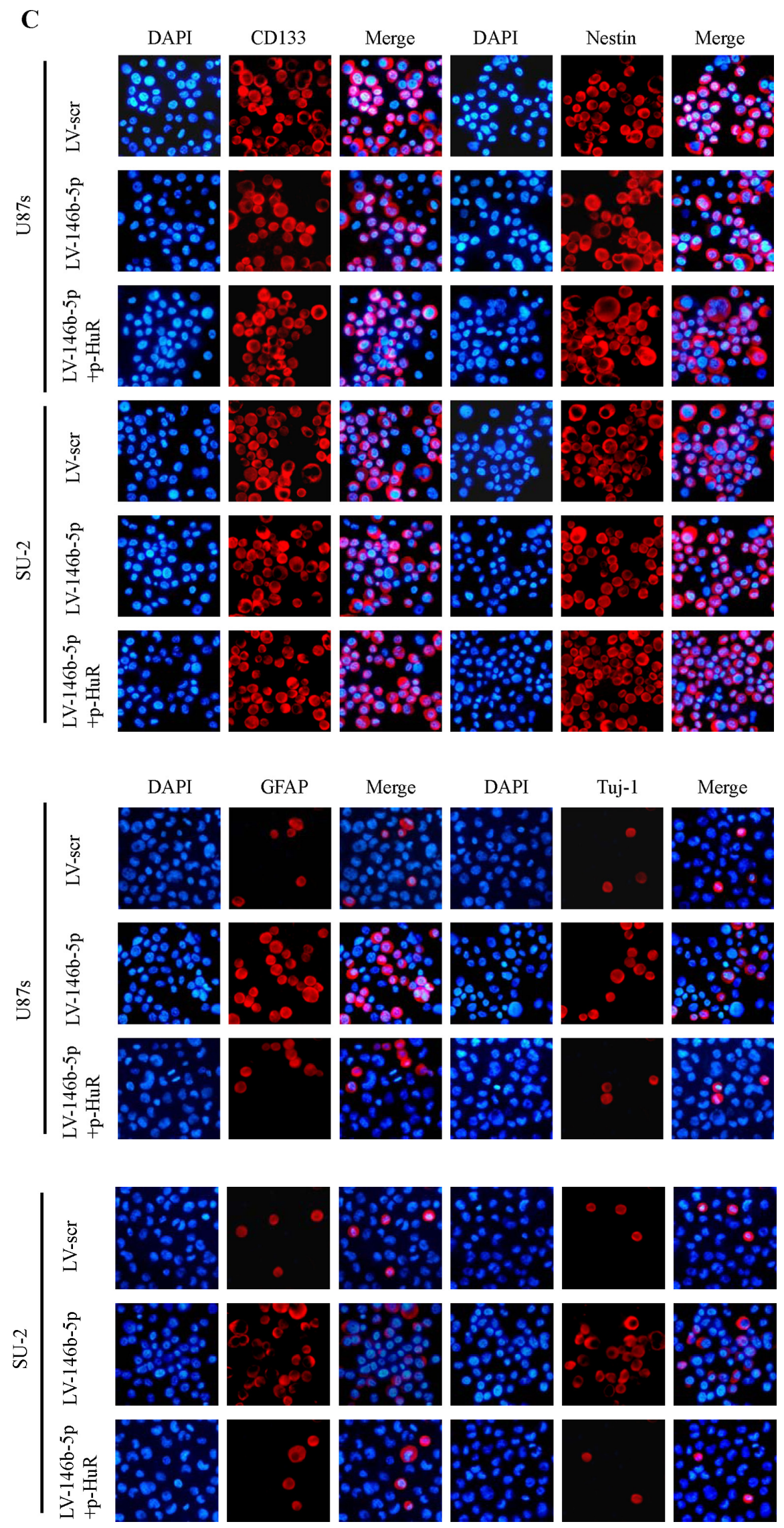

Figure 10 (Continued): C. Immunofluoresence staining for CD133, nestin, GFAP and Tuj-1. 
bearing mice were monitored daily until neurologic signs occurred in each animal. When 300 or 3,000 cells were injected, the tumor incidence of GSCs with miR-146b-5p overexpression decreased compared with that of GSCs expressing scramble sequence, and the tumor incidence of GSCs decreased after 8 Gy X-ray irradiation (Figure 12A). After transfection with $\mathrm{p}-\mathrm{HuR}$, the tumor incidence of GSCs with miR-146b-5p overexpression increased. Survival of mice with GSCs overexpressing miR-146b$5 \mathrm{p}$ increased compared to that with GSCs expressing scramble sequence. Nevertheless, survival of mice with GSCs overexpressing miR-146b-5p and HuR decreased compared with that of GSCs overexpressing miR-146b5 p. Kaplan-Meier curves also demonstrated increment in survival with the coming of miR-146b-5p overexpression and/or 8 Gy X-ray irradiation (Figure 12B). Three weeks after $3 \times 10^{4}$ GSCs transplanted, the photon measurement around the tumor area showed by in vivo imaging system (IVIS) decreased with introduction of miR-146b-5p overexpression and/or 8 Gy X-ray irradiation (Figure 12C). In microscopic observation of tumors, lesser number of Ki-67 and CD31-positive cells and more number of TUNEL-positive cells were observed in miR-146b-5p overexpression group compared with scramble sequence

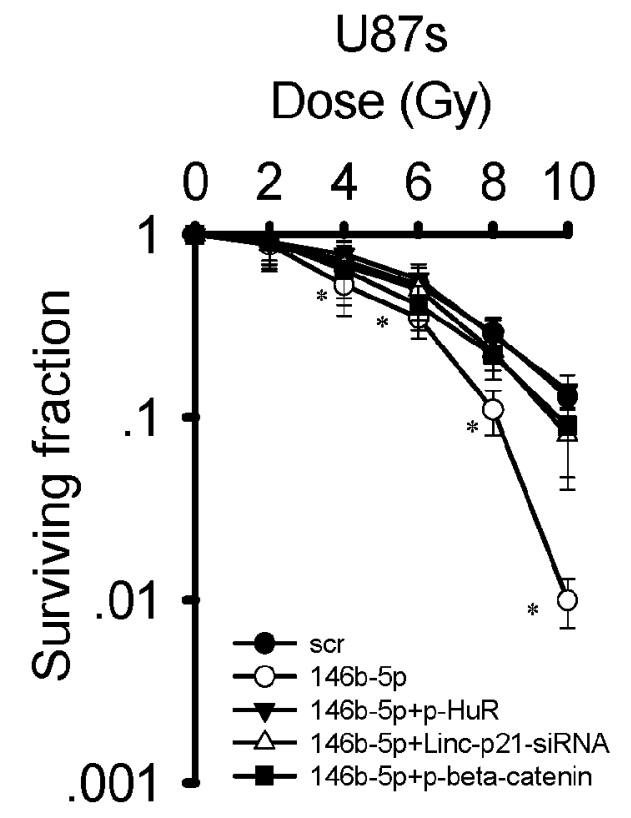

group, while the number of Ki-67, CD31 and TUNELpositive cells in miR-146b-5p and HuR overexpression group showed no significant changes compared with scramble sequence group (Figure 12D). The results indicated that miR-146b-5p overexpression may result in glioma growth delay through reducing cell proliferation and angiogenesis and inducing apoptosis. These in vivo data suggested that miR-146b-5p overexpression could reduce tumorigenic capacity of GSCs and increase survival in mouse models of human glioma.

\section{DISCUSSION}

MiR-146b-5p expression has been found in almost all human organs [38]. In papillary thyroid carcinoma and lung cancer, it acts as an oncogene and has been regarded as a relevant diagnostic marker [39, 40]. However, in glioma and some other cancers, miR-146b-5p expression is downregulated and acts as an tumor suppressor gene [41]. A recent study revealed that miR-146b-5p inhibited proliferation and promoted apoptosis of glioma, and predicted better prognosis in human gliomas, especially in glioblastoma. Its downregulation was a main reason of glioma genesis and malignant progression [42].
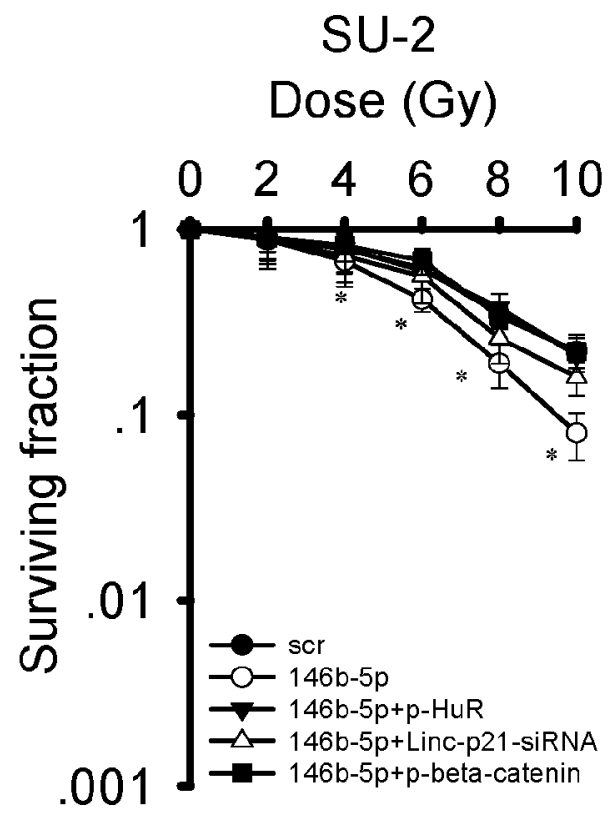

\begin{tabular}{|c|c|c|c|c|c|}
\hline & $\mathrm{scr}$ & $146 b-5 p$ & $\begin{array}{c}146 \mathrm{~b}-5 \mathrm{p}+ \\
\mathrm{p}-\mathrm{HuR}\end{array}$ & $\begin{array}{c}\text { 146b-5p+Linc- } \\
\text { p21-siRNA }\end{array}$ & $\begin{array}{l}146 \mathrm{~b}-5 \mathrm{p}+ \\
\mathrm{p}-\beta \text {-catenin }\end{array}$ \\
\hline U87s $D_{0}$ & $3.40 \mathrm{~Gy}$ & $2.47 \mathrm{~Gy}$ & $2.99 \mathrm{~Gy}$ & 3.09 Gy & $2.93 \mathrm{~Gy}$ \\
\hline SU-2 $D_{0}$ & $3.82 \mathrm{~Gy}$ & $2.86 \mathrm{~Gy}$ & $3.85 \mathrm{~Gy}$ & $3.50 \mathrm{~Gy}$ & $3.23 \mathrm{~Gy}$ \\
\hline
\end{tabular}

Figure 11: MiR-146b-5p overexpression decreased radioresistance of GSCs. After exposure to 0, 2, 4, 6, 8 and 10 Gy X-ray irradiation, cell survival fractions were examined and the survival curves of cells were obtained from data fitting according to the linear

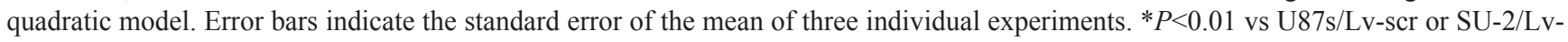
scr. $\mathrm{D}_{0}$ (mean lethal dose) was calculated by the linear quadratic model. 
Consistent with these results, we found miR-146b-5p was down-regulated in GSCs compared to non-GSCs glioma cells and its overexpression could suppress stemness and radioresistance of GSCs by targeting HuR, which was verified as a miR-146b-5p target in GSCs by bioinformatic analysis, real-time PCR, and luciferase reporter assay in the present study.

HuR, a ubiquitous RNA binding protein (RBP), influences cell proliferation, survival and carcinogenesis through its RNA recognition motifs binding to adenine and uridine (AU)-rich stability elements (ARE) in 3'-UTR of mRNA [43]. Instead of acting as an RNA stabilizer, HuR works with the Ago 2 protein and let-7 to destabilize lincRNA-p21 [22]. Many studies have reported elevated expression of HuR in numerous malignancies [44]. In this study, we found that HuR expression was up-regulated in GSCs compared with non-GSCs glioma cells, which resulted in lincRNA-p21 down-regulation, leading to elevated $\beta$-catenin expression in GSCs. The mRNA of c-myc, a target gene of $\beta$-catenin, has been verified as a

A

\begin{tabular}{|l|l|l|l|l|l|l|l|l|l|l|l|l|}
\hline & \multicolumn{3}{|c|}{ U87s } & \multicolumn{3}{c|}{ SU-2 } & \multicolumn{3}{c|}{ U87s+8 Gy } & \multicolumn{3}{c|}{ SU-2+8 Gy } \\
\cline { 2 - 13 } & $3 \times$ & $3 \times$ & $3 \times$ & $3 \times$ & $3 \times$ & $3 \times$ & $3 \times$ & $3 \times$ & $3 \times$ & $3 \times$ & $3 \times$ & $3 \times$ \\
& $10^{2}$ & $10^{3}$ & $10^{4}$ & $10^{2}$ & $10^{3}$ & $10^{4}$ & $10^{2}$ & $10^{3}$ & $10^{4}$ & $10^{2}$ & $10^{3}$ & $10^{4}$ \\
\hline LV-scr & $3 / 5$ & $4 / 5$ & $5 / 5$ & $3 / 5$ & $4 / 5$ & $5 / 5$ & $1 / 5$ & $3 / 5$ & $5 / 5$ & $1 / 5$ & $3 / 5$ & $5 / 5$ \\
Incidence & 42 & 32 & 24 & 49 & 38 & 28 & - & 39 & 27 & - & 41 & 31 \\
Median Survival & $4 / 5$ & $3 / 5$ & $5 / 5$ & $1 / 5$ & $3 / 5$ & $5 / 5$ & $0 / 5$ & $1 / 5$ & $5 / 5$ & $0 / 5$ & $1 / 5$ & $5 / 5$ \\
\hline $\begin{array}{l}\text { LV-miR-146b-5p } \\
\text { Incidence }\end{array}$ & $1 / 5$ & - & 50 & - & 54 & 36 & - & - & 41 & - & - & 43 \\
Median Survival & - & & & & & & & & & & & \\
\hline $\begin{array}{l}\text { LV-miR-146b-5p } \\
\text { +p-HuR }\end{array}$ & & & & & & & & & & & & \\
Incidence & $3 / 5$ & $4 / 5$ & $5 / 5$ & $2 / 5$ & $4 / 5$ & $5 / 5$ & $1 / 5$ & $3 / 5$ & $5 / 5$ & $1 / 5$ & $2 / 5$ & $5 / 5$ \\
Median Survival & 44 & 34 & 25 & 51 & 41 & 30 & - & 42 & 30 & - & 46 & 34 \\
\hline
\end{tabular}

B
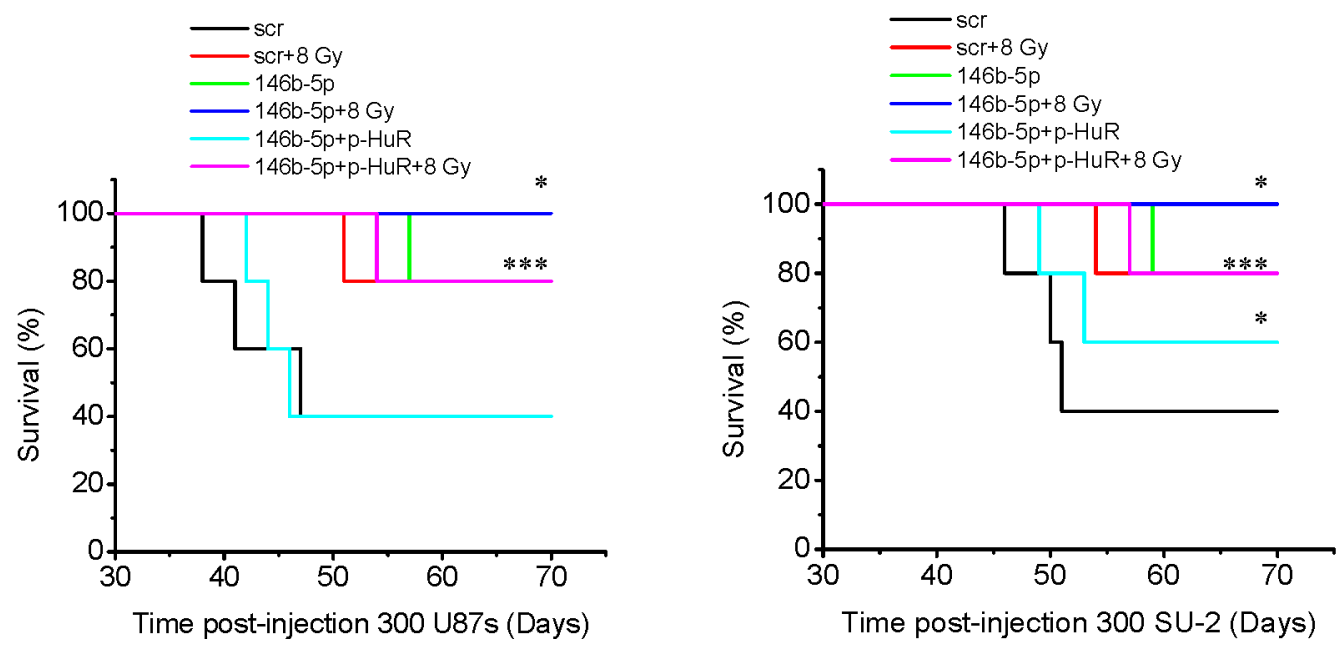

Figure 12: MiR-146b-5p overexpression reduces tumorigenic capacity of GSCs. A. Tumor incidence of GSCs and median survival of nude mice bearing human GSCs. B. Kaplan-Meier curves of mice bearing human GSCs. ${ }^{*} P<0.05$ vs Lv-scr.

(Continued) 
C
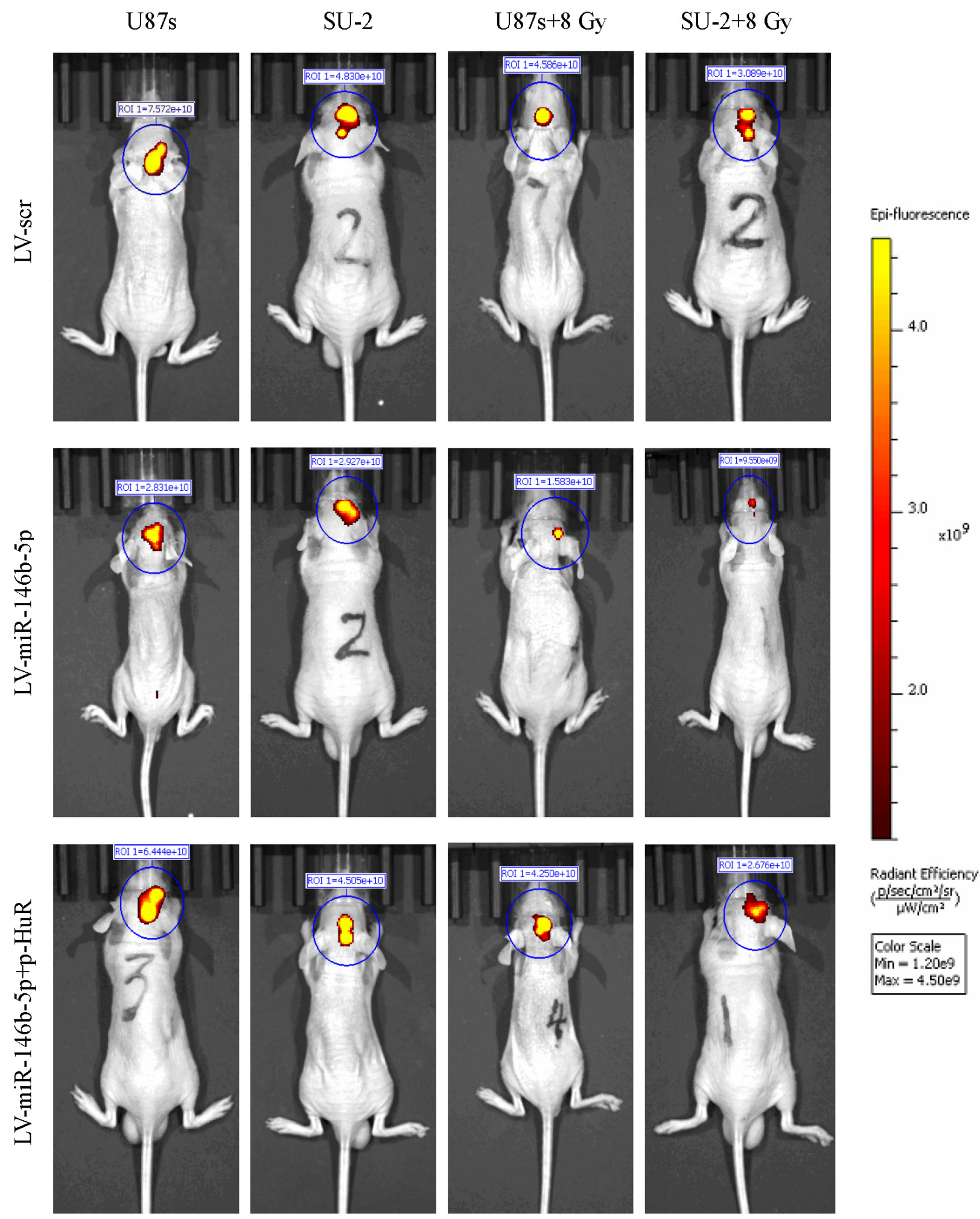

Radiant EFiciency (Pisecicm $2 / 5$ )

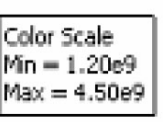

Figure 12 (Continued): C. Photon measurement around the tumor area showed by in vivo imaging system (IVIS). 


\section{D}

LV-scr

$\mid$

ڤิ)

$(\times 400)$

TUNEL
$(\times 400)$

TUNEL
$(\times 400)$

$(\times 200)$

Ki-67

$(\times 400)$

$(\times 200)$

$(\times 400)$
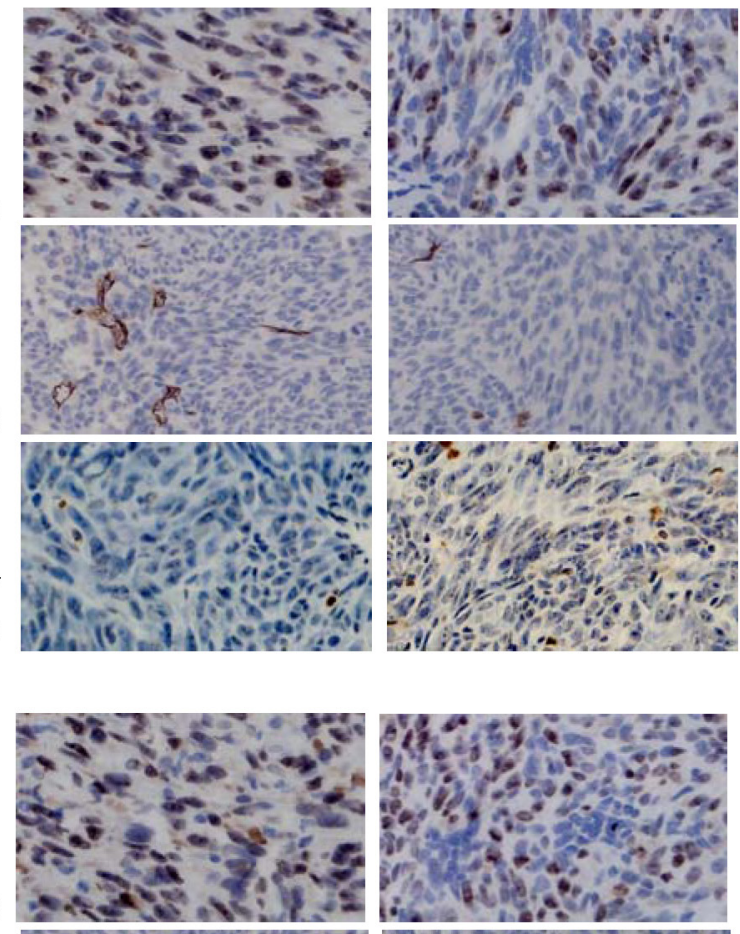

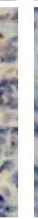
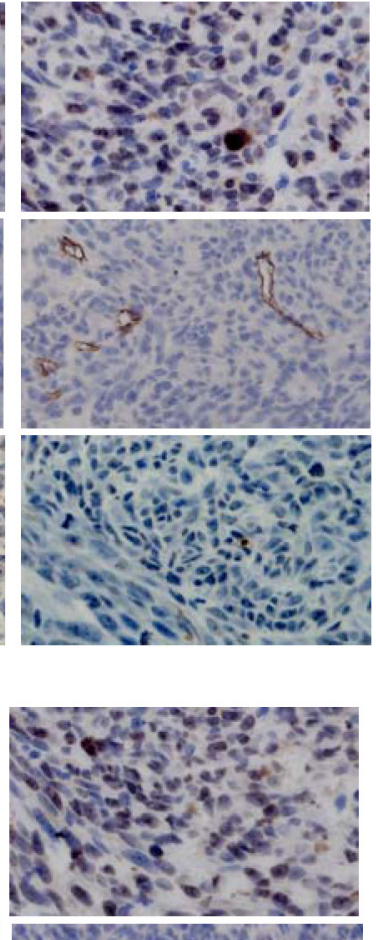
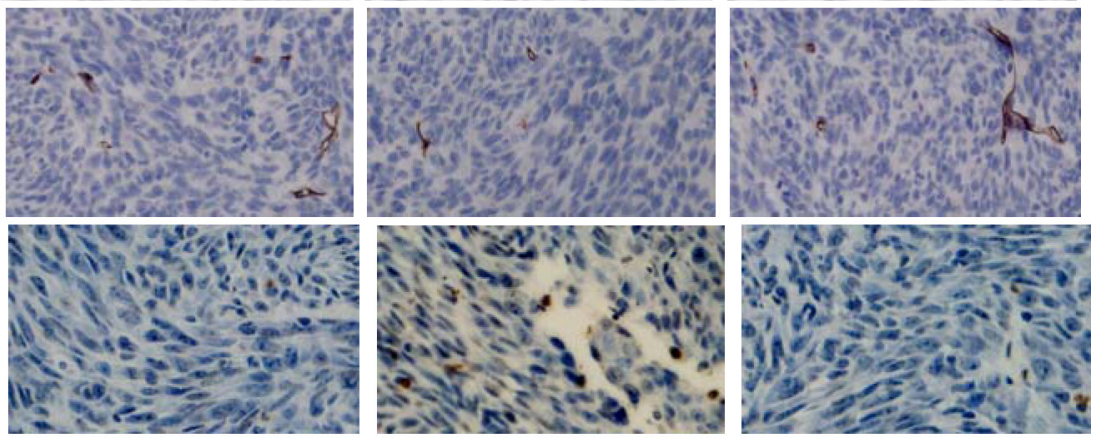

Figure 12 (Continued): D. Ki-67, CD31 and TUNEL staining of tumor sections.

target of HuR [45]. Kim et al. further revealed that the site bound by HuR are proximal to that bound by let- 7 in 3'-UTR of c-myc, which suggested that HuR might recruit let-7-loaded RNA-induced silencing complex to inhibit c-myc expression in HeLa cells [46]. Thus, the effect of HuR on c-myc expression might be direct binding c-myc mRNA and supressing translation in cervical carcinoma, besides its indirect influence through lincRNA-p21/3catenin revealed in this study.

In order to target the aberrant HuR/lincRNA-p21/ $\beta$ catenin pathway in GSCs, We employed lentiviral vector to overexpress miR-146b-5p and analyzed GSCs phenotypic changes. We found that miR-146b-5p overexpression increased apoptosis and radiosensitivity, and decreased cell viability, neurosphere formation capacity and stem cell marker expression in GSCs. Moreover, knock-down lincRNA-p21 or HuR and $\beta$-catenin overexpression could rescue the phenotypic changes resulting from miR-146b$5 \mathrm{p}$ overexpression in GSCs. These results demonstrated that miR-146b-5p played a vital role in GSC stemness, survival, and radioresistance in vitro, so we further evaluated the ability of miR-146b-5p overexpression to improve the survival of immuno-compromised mice bearing human GSCs. The in vivo data showed that miR-146b-5p overexpression could reduce tumor-initiating potential of GSCs and increase survival in mice bearing human GSCs.

In conclusion, $\beta$-catenin signaling pathway is frequently activated through the miR-146b-5p/HuR/ lincRNA-p21 axis in GSCs, which contributes to stemness and radioresistance of GSCs. Our data suggest that targeting the miR-146b-5p/HuR/lincRNA-p21/ $\beta$-catenin signaling pathway may be valuable therapeutic strategies against glioma. 


\section{MATERIALS AND METHODS}

\section{Patient samples}

The present study consisted of 37 glioma tissues and 8 normal brain tissues, which were resected at the department of neurosurgery of the first affiliated hospital of Jilin University between 2013 and 2014. None of the patients received preoperative treatment such as irradiation or chemotherapy. All research protocols in the present study were approved by the Ethics Committee of the first affiliated hospital of Jilin University.

\section{Cell culture}

Normal human astrocytes (NHA, ScienCell Research Laboratories, Carlsbad, CA) were cultured in a growth medium containing 3\% fetal bovine serum, 25 $\mu \mathrm{g} / \mathrm{ml}$ bovine insulin, $20 \mathrm{ng} / \mathrm{ml}$ epidermal growth factor (EGF), $20 \mathrm{ng} / \mathrm{ml}$ progesterone, and $50 \mu \mathrm{g} / \mathrm{ml}$ transferrin at $37^{\circ} \mathrm{C}$ in $5 \% \mathrm{CO}_{2}, 90 \%$ relative humidity. The human glioma cell lines U87 were purchased from the Type Culture Collection of the Chinese Academy of Sciences and cultured in DMEM/F12 medium (1:1, Hyclone) supplemented with $10 \%$ fetal bovine serum (FBS) (Invitrogen) in a humidified atmosphere containing 5\% $\mathrm{CO} 2$ at $37^{\circ} \mathrm{C}$. The human GSCs culture U87s, derived from glioma cell line U87, were enriched using serum-free clone formation method with stem cell medium, which has been previously described [33]. The patient-derived GSCs culture SU-2 and non-GSCs glioma cell culture NSSU2 , isolated from a surgical specimen of a 52-year-old female patient with glioblastoma, were kindly provided by Dr. Ting Sun in neurosurgery laboratory of the first affiliated hospital of Soochow University [33, 47, 48]. GSCs were cultured as spheres in serum-free DMEM/F12 supplemented with 2\% B27 Neuro Mix (invitrogen), 20 $\mathrm{ng} / \mathrm{mL}$ epidermal growth factor (EGF) and $10 \mathrm{ng} / \mathrm{mL}$ basic fibroblast growth factor (bFGF) (PeproTech). The cultures were fed every 3 days with one-third volume of fresh medium. Cell passaging was performed by dissociation of spheres using NeuroCult chemical dissociation kit (StemCell Technologies). Neurospheres of around 8-12 passages were used for this study.

\section{Real-time reverse transcription-polymerase chain reaction (RT-PCR)}

Total RNA from brain tissues and glioma cells and tissues were extracted using TRIzol (invitrogen), and cDNA was generated using the First Strand cDNA Synthesis kit (Roche), according to the manufacturer's instructions. mRNA expression was analyzed using the SYBR Green PCR Master Mix (Applied Biosystems) on a 7300 Real-Time PCR System (Applied Biosystems, Foster City, CA) using standard conditions as previously described [33]. Fold changes in mRNA expression were quantified with the $2^{-\Delta \Delta C T}$ relative quantification method using $\beta$-actin as house keeping control. The primer sequences used were as follows: LincRNA-p21 forward, 5'-CCATCCACCTACATCACGAAG-3' and reverse, 5'-CTCTGGAGAACCCCGACTAAT-3'. $\beta$-catenin forward, 5'-ATTGTCCACGCTGGATTTTC-3' and reverse, 5'-TCGAGGACGGTCGGACT-3'. C-Myc forward, 5'-CGCTTCTCTGAAAGGCTCTCCTTG-3' and reverse, 5'-GAGTCGTAGTCGAGGTCATAGTTC-3'. Cyclin D1 forward, 5'-AGGAGAACAAACAG ATCA3' and reverse, 5'-TAGGACAGGAAGTTGTTG-3'. HuR forward, 5'-AGACATGTTCTCTCGGTTTG-3' and reverse, 5'-ACTGAACCTGACCGTACAACTGGTAA TTGCCTCTTCTG-3'. MiRNA detection by real-time analysis involved reverse transcription of cDNA using a small RNA specific stem-loop RT primer. Once specific cDNA was generated, individual miRNA expression was assessed by real-time PCR according to the TaqMan MicroRNA Assay. Results were normalized to small nuclear RNA U6 that served as control and the data were expressed as Log 2 fold change in respective miR/U6 snRNA levels.

\section{Western blot analysis of protein expression}

Western blotting was performed using standard procedures. The following primary antibodies were used: mouse monoclonal anti- $\beta$-catenin, c-myc, Cyclin D1, Hu antigen R (HuR), Phospho-AKT, Total-AKT, mammalian target of rapamycin (mTOR), B-cell-specific Moloney murine leukemia virus insertion site 1 (Bmi1), glial fibrillary acidic protein (GFAP), Lamin b1 and $\beta$-actin (Santa Cruz Inc. California, USA). Experiments were repeated three times. The relative levels of protein expression were normalized against protein levels of an internal control gene, $\beta$-actin, performed in the same run.

\section{Subcellular fractionation}

Cells were homogenized in hypotonic buffer (10 $\mathrm{mM}$ Tris- $\mathrm{HCl}, \mathrm{pH}$ 7.8, $150 \mathrm{mM} \mathrm{NaCl}$, and $1 \mathrm{mM}$ EDTA) containing $0.1 \%(\mathrm{w} / \mathrm{v})$ Triton X-100. The lysates were centrifuged at $3000 \mathrm{rpm}$ for $10 \mathrm{~min}$ at $4^{\circ} \mathrm{C}$. The pellet was re-suspended in hypotonic buffer and re-centrifuged and was used as the nuclear fraction. The supernatant fraction was re-centrifuged at $16,000 \mathrm{rpm}$ for $20 \mathrm{~min}$ at $4^{\circ} \mathrm{C}$ and used as the cytoplasmic fraction.

\section{Chromatin immunoprecipitation}

Cells were crosslinked with $1 \%$ formaldehyde, harvested, resuspended in lysis buffer supplemented with 1 mM PMSF, and sonicated. The chromatin fragments were immunoprecipitated using either p53 or IgG (Millipore, MA, USA) antibodies. After extensive washing steps, the formaldehyde crosslinks were reversed by treatment at $65^{\circ} \mathrm{C}$. DNA was purified by phenol/chloroform extraction 
followed by ethanol precipitation and samples were used in real-time PCR.

\section{siRNA design and transfection}

The cDNA sequences of AKT and mTOR were obtained from GenBank (NM 001014431 and 004958). The siRNA target design tools from Ambion were used to design siRNA. AKT-siRNA was designed and synthesized as follows: sense: 5'-CGGUAGCACUUGACCUUUUTT-3', antisense: 5'-AAAAGGUCAAGUGCUACCGTG-3'. mTORsiRNA was designed and synthesized as follows: sense: 5'-CAUUCGCAUUCAGUCCAUATT-3', antisense: 5'-UAUGGACUGAAUGCGAAUGAT-3'. The sequence of LincRNA-p21 was previously reported [18] and LincRNA-p21-siRNA was designed and synthesized as follows: sense: 5'-UGAAAAGAGCCGUGAGCUATT-3', antisense: 5'-UAGCTCACGGCUCUUUUCAAT-3' (Sangon Inc. Shanghai, China). Cells were plated 24 $\mathrm{h}$ prior to transfection and were transfected in 6-well plates by use of Lipofectamine RNAiMAX (Invitrogen, Carlsbad, CA, USA). AKT, mTOR and LincRNA-p21siRNA and negative control siRNA (nc-siRNA) were used at $100 \mathrm{nM}$ final concentration.

\section{Luciferase reporter assay}

The 3'UTR of HuR gene contains a putative miR-146b-5p-target site: 5'-AAGAUUAACCCUC AAAGUUCUCU-3'. The wild type and mutated 3'UTRs of HuR were amplified by PCR from cDNA of U87s cells and were ligated into the pGL3 basic luciferase expression vector (pGL3-Luc) (Promega, Madison, WI, USA) at the 3'-end of the luciferase coding sequence. The pGL3-Luc vector containing wild type and mutated 3'UTRs of HuR and the internal control vector pRL-TK (Promega) were co-transfected into U87s and SU-2 cells. Twenty four hours later, $20 \mathrm{nM}$ of miR-146b-5p oligos (5'-UGAGAACUGAAUUCCAUAGGCU-3') or scramble oligos (5'-UUCUCCGAACGUGUCACGUTT-3') (GenePharma Co. Shanghai, China) were transfected into U87s and SU-2 cells. Luciferase activity was measured 48 $\mathrm{h}$ after vectors transfection using Dual-luciferase Reporter Assay System (Promega) according to the manufacturer's instructions.

\section{Generation of stable cell lines}

GSCs with stable integration of the miR-146b-5p mature sequence or scramble sequence were generated through lentiviral-mediated gene transfer [33]. To generate the respective viruses, 293T cells were transfected with the lentiviral vector, pGLV-miR-146b-5p-GFP or pGLVscr-GFP, and the packaging plasmid PG-P1-VSVG, PGP2-REV and PG-P3-RRE according to standard protocols. The target GSCs were infected with viruses encoding either miR-146b-5p or scramble sequence and selected using puromycin. After 4 weeks, single clones were analyzed for positive green fluorescent protein (GFP) signals. The positive clones were expanded for additional testing.

\section{mRNA decay studies}

Actinomycin D (Sigma, St Louis, MO, USA) was added to the media at a concentration of $5 \mu \mathrm{g} / \mathrm{ml}$ to arrest transcription at time zero. Cells were harvested for RNA analysis at $0,1,2$, and $3 \mathrm{~h}$. The half-life of each mRNA was calculated using the following formula: $\mathrm{t}_{1 / 2}=\ln 2 /$ $\mathrm{k}_{\text {decay }}$. The decay rate constant $\left(\mathrm{k}_{\text {decay }}\right)$ was obtained from fitting the changes of mRNA concentration with respect to time to a first order decay model using a least squared differences method [49].

\section{LincRNA-p21, HuR and $\beta$-catenin expression vectors construction and transfection}

Full-length cDNA of LincRNA-p21, HuR and $\beta$-catenin were isolated from cDNA of U87s cells and were amplified through RT-PCR using specific primers. The primer sequences used were as follows: LincRNA-p21 forward, 5'-TGGCAGTCTGACCCAC ACTCCCCACGCCC-3' and reverse, 5'-ACAGTGCA CAGACAATCATACACACGTGT-3'. HuR forward, 5'-ATGGTCTAA TGGTTATGAAGAC-3' and reverse, 5'-TTTGTGGACTTGTTGGTTTTG-3'. $\quad \beta$-catenin forward, 5'-AAAATCCAGCGTGGACAATGG-3' and reverse, 5'-TGTGGCAAGTTCTGCATCATC-3'. The amplified cDNA fragment were sub-cloned into the pcDNA3.1(+) vectors. The recombinant vectors were confirmed by the digestion analysis of restriction endonuclease and inserted sequences were verified by DNA sequencing. Cells were transfected in 6-well plates by use of Lipofectamine 2000 (Invitrogen, Carlsbad, CA, USA).

\section{Cell viability assay}

GSCs viability was measured by a 3-(4, 5-dimethylthiazol-2-yl)-2, 5-diphenyl tetrazolium bromide (MTT) assay (Sigma, St Louis, MO, USA) after 2, 4 and 6 days culture. GSCs viability was calculated as a ratio of OD value, and the cell viability of GSCs/Lv-scr after different periods of culture were taken as $100 \%$.

\section{Flow cytometric analysis of cell cycle and apoptosis}

GSCs were harvested and fixed overnight with $70 \%$ ethanol at $4{ }^{\circ} \mathrm{C}$, followed by resuspension in $500 \mu \mathrm{L}$ of PBS. After addition of $10 \mu \mathrm{L}$ RNase $(10 \mathrm{mg} / \mathrm{mL})$, cells were left for 30 minutes at $37^{\circ} \mathrm{C}$ and stained with $10 \mu \mathrm{L}$ propidium iodide $(1 \mathrm{mg} / \mathrm{mL})$. Cellular DNA content was 
determined on a flow cytometer Beckton Dickinson $(B D)$ FACScan (BD Biosciences, San Jose, CA). Quantification of apoptotic cells was performed according to the AnnexinV-PE/7-AAD Apoptosis Detection Kit manufacturer instructions (KeyGen Biotech. Nanjing, China). Analyses were performed by a flow cytometer (BD FACScan). Phycoerythrin (PE) -positive and 7-amino-actinomycin D (7-AAD) -negative cells were regarded as apoptotic cells.

\section{Neurosphere formation assay}

GSCs were plated at 10,100 or 1000 cells per well in 96-well plates. After culture for $12 \mathrm{~d}$, the number of neurospheres that contained more than 20 cells in each well was determined, and neurosphere formation rate was calculated as the number of neurospheres/100 $\times 100 \%$.

\section{Flow cytometry analysis and immunofluoresence staining for the stem cell markers and the differentiation markers}

For flow cytometry analysis, GSCs enriched in DMEM/F12 medium supplemented with growth factors were dissociated, washed, and incubated with PEconjugated CD133, nestin and GFAP antibody (Milteny Biotech) in phosphate-buffered saline (PBS)-BSA for $1 \mathrm{~h}$. Labeled cells were resuspended in PBS with $1 \%$ FBS, and analyzed by a flow cytometer Beckton Dickinson $(B D)$ FACScan (BD Biosciences, San Jose, CA). Isotypic IgG and unstained cells served as negative controls.

For immunofluoresence staining analysis, GSCs were fixed in 4\% paraformaldehyde (Sigma-Aldrich) for 15 minutes at room temperature, permeabilized using $0.1 \%$ Triton-X100 (Sigma-Aldrich) for $20 \mathrm{~min}$ and blocked in $5 \%$ Bovine serum albumin (BSA) (Sigma-Aldrich) for $1 \mathrm{~h}$ at room temperature. Then the GSCs were immunostained with mouse antibodies against human CD133 (1:200, Santa Cruz), nestin (1:300, Santa Cruz), glial fibrillary acidic protein (GFAP, 1:500, Abcam) and Tuj-1 (1:500, Abcam) for $45 \mathrm{~min}$ in darkness. Subsequent visualization for the stem cell markers, CD133 and nestin, and the differentiation markers, GFAP (astrocytes) and Tuj-1 (neurons), were performed with Texas Red-conjugated anti-mouse $\operatorname{IgG}$ (1:1000, Vector Laboratories) for $30 \mathrm{~min}$ at room temperature and the nuclei were counterstained with 4',6'-diamidino-2-phenylindole (DAPI, 1:500, Santa Cruz). Fluorescence images were captured with fluorescence microscope (Olympus BX50).

\section{Clonogenic cell survival assay}

Cells were irradiated with X-ray (6 MV, the dose rate was $200 \mathrm{cGy} / \mathrm{min}$ ) by a PRIMUS accelerator (SIEMENS Medical Solutions, Erlangen, Germany) at room temperature. After irradiation, a specific number of cells (100 for cells irradiated with 0 or $2 \mathrm{~Gy}, 200$ for
4 Gy and 2000 for 6, 8 and 10 Gy) was plated in petri dishes in triplicate for clonogenic assay. Then the cells were incubated for 12 days. Colonies were fixed by $37 \%$ formaldehyde solution and stained with crystal violet and colonies of more than 50 cells were counted. Furthermore, the cell survival fraction was counted out and the mean lethal dose $\left(\mathrm{D}_{0}\right)$ was calculated by the linear quadratic model.

\section{Orthotopic transplantation assays}

For intracranial implantation, $36 \mathrm{~h}$ after irradiation with 8 Gy X-ray, GSCs/Lv-scr, GSCs/Lv-miR-146b-5p and GSCs/Lv-miR-146b-5p+p-HuR cells were counted and the indicated numbers of GSCs were implanted into the right frontal lobes of 6-8-week-old female athymic nude mice (Experimental Animals Center of Shanghai Institute of Life Science, Shanghai, China).

Three weeks later, the Xenogen in vivo imaging system (IVIS) 50 system was used to visualize tumors, and photon measurement was defined around the tumor area and quantified using Living Image software (Caliper Life Science SA, Villepinte, France). The mice used for immunohistochemical studies were sacrificed three weeks after implantation. Tumor tissues were fixed and imbedded in paraffin. Tumor sections of $5 \mu \mathrm{m}$ were cut from the embedded tissue and incubated with specific primary antibodies, including rabbit polyclonal antibody to human Ki-67 (KeyGen Biotech.) and mouse CD31 (eBioscience, Inc., San Diego, CA, USA) for $1 \mathrm{~h}$ at $37^{\circ} \mathrm{C}$ followed by overnight at $4^{\circ} \mathrm{C}$ in humidity chamber. Negative controls were incubated only with universal negative control antibodies under identical conditions. The sections were then incubated with appropriate biotinylated secondary antibody for $60 \mathrm{~min}$ at room temperature. Thereafter, sections were incubated with conjugated horseradish peroxidase streptavidin (KeyGen Biotech.) for $60 \mathrm{~min}$, followed with 3,3'-diaminobenzidine (Sigma) working solution, and counterstained with hematoxylin. Apoptotic cells in tumor tissues were detected by terminal deoxynucleotidyl transferase (TdT)-mediated dUTP-biotin nick end labeling (TUNEL) stain, using an In Situ Cell Death Detection Kit (KeyGen Biotech.) following the manufacturer's specifications. All the animal experiments were conducted in accordance with Guidelines for the Welfare of Animals in Experimental Neoplasia.

\section{Statistical analysis}

All statistical parameters were calculated with GraphPad Prism 6.01 (GraphPad Software Inc.). Student's $\mathrm{t}$ test was used for most data analysis. For comparisons among more than two groups, One-way Analysis of Variance (ANOVA) followed by Bonferroni post-test was performed. Mice survival were evaluated by the Kaplan- 
Meier method and analyzed by the log-rank test. $P<0.05$ was considered to be statistically different.

\section{ACKNOWLEDGMENTS AND FUNDING}

This work was supported by the National Natural Science Foundation of China (No. 31570851, 81201742 and 81071958) and Priority Academic Program Development of Jiangsu Higher Education Institutions (PAPD).

\section{CONFLICTS OF INTEREST}

The authors report no conflicts of interest.

\section{REFERENCES}

1. Seymour T, Nowak A, Kakulas F. Targeting Aggressive Cancer Stem Cells in Glioblastoma. Front Oncol. 2015; 5: 159.

2. Lathia JD, Mack SC, Mulkearns-Hubert EE, Valentim CL, Rich JN. Cancer stem cells in glioblastoma. Genes Dev. 2015; 29: 1203-1217.

3. Sørensen MD, Fosmark S, Hellwege S, Beier D, Kristensen BW, Beier CP. Chemoresistance and chemotherapy targeting stem-like cells in malignant glioma. Adv Exp Med Biol. 2015; 853: 111-138.

4. Rizzo AE, Yu JS. Radiation therapy for glioma stem cells. Adv Exp Med Biol. 2015; 853: 85-110.

5. Venere M, Horbinski C, Crish JF, Jin X, Vasanji A, Major J, Burrows AC, Chang C, Prokop J, Wu Q, Sims PA, Canoll $\mathrm{P}$, Summers MK, et al. The mitotic kinesin KIF11 is a driver of invasion, proliferation, and self-renewal in glioblastoma. Sci Transl Med. 2015; 7: 304ra143.

6. Hitomi M, Deleyrolle LP, Mulkearns-Hubert EE, Jarrar A, Li M, Sinyuk M, Otvos B, Brunet S, Flavahan WA, Hubert CG, Goan W, Hale JS, Alvarado AG, et al. Differential connexin function enhances self-renewal in glioblastoma. Cell Rep. 2015; 11: 1031-1042.

7. Xie Q, Wu Q, Mack SC, Yang K, Kim L, Hubert CG, Flavahan WA, Chu C, Bao S, Rich JN. CDC20 maintains tumor initiating cells. Oncotarget. 2015; 6: 13241-13254. doi: 10.18632/oncotarget.3676.

8. Jackson M, Hassiotou F, Nowak A. Glioblastoma stemlike cells: at the root of tumor recurrence and a therapeutic target. Carcinogenesis. 2015; 36: 177-185.

9. Schonberg DL, Miller TE, Wu Q, Flavahan WA, Das NK, Hale JS, Hubert CG, Mack SC, Jarrar AM, Karl RT, Rosager AM, Nixon AM, Tesar PJ, et al. Preferential Iron Trafficking Characterizes Glioblastoma Stem-like Cells. Cancer Cell. 2015; 28: 441-455.

10. Fan Y, Potdar AA, Gong Y, Eswarappa SM, Donnola S, Lathia JD, Hambardzumyan D, Rich JN, Fox PL. Profilin-1 phosphorylation directs angiocrine expression and glioblastoma progression through HIF- $1 \alpha$ accumulation. Nat Cell Biol. 2014; 16: 445-456.
11. Zhou W, Ke SQ, Huang Z, Flavahan W, Fang X, Paul J, Wu L, Sloan AE, McLendon RE, Li X, Rich JN, Bao S. Periostin secreted by glioblastoma stem cells recruits M2 tumour-associated macrophages and promotes malignant growth. Nat Cell Biol. 2015; 17: 170-182.

12. Tsai MC, Spitale RC, Chang HY. Long intergenic noncoding RNAs: new links in cancer progression. Cancer Res. 2011; 71: 3-7.

13. Yarmishyn AA, Kurochkin IV. Long noncoding RNAs: a potential novel class of cancer biomarkers. Front Genet. 2015; 6: 145.

14. Tang SS, Zheng BY, Xiong XD. LincRNA-p21: Implications in Human Diseases. Int J Mol Sci. 2015; 16: 18732-18740.

15. Hall JR, Messenger ZJ, Tam HW, Phillips SL, Recio L, Smart RC. Long noncoding RNA lincRNA-p21 is the major mediator of UVB-induced and p53-dependent apoptosis in keratinocytes. Cell Death Dis. 2015; 6: e1700.

16. Dimitrova N, Zamudio JR, Jong RM, Soukup D, Resnick R, Sarma K, Ward AJ, Raj A, Lee JT, Sharp PA, Jacks T. LincRNA-p21 activates p21 in cis to promote Polycomb target gene expression and to enforce the G1/S checkpoint. Mol Cell. 2014; 54: 777-790.

17. Yang F, Zhang H, Mei Y, Wu M. Reciprocal regulation of HIF-1 $\alpha$ and lincRNA-p21 modulates the Warburg effect. Mol Cell. 2014; 53: 88-100.

18. Huarte M, Guttman M, Feldser D, Garber M, Koziol MJ, Kenzelmann-Broz D, Khalil AM, Zuk O, Amit I, Rabani M, Attardi LD, Regev A, Lander ES, et al. A large intergenic noncoding RNA induced by p53 mediates global gene repression in the p53 response. Cell. 2010; 142: 409-419.

19. Wang G, Li Z, Zhao Q, Zhu Y, Zhao C, Li X, Ma Z, Li $X$, Zhang Y. LincRNA-p21 enhances the sensitivity of radiotherapy for human colorectal cancer by targeting the Wnt/ $\beta$-catenin signaling pathway. Oncol Rep. 2014; 31: 1839-1845.

20. Yang N, Fu Y, Zhang H, Sima H, Zhu N, Yang G. LincRNA-p21 activates endoplasmic reticulum stress and inhibits hepatocellular carcinoma. Oncotarget. 2015; 6: 28151-28163. doi: 10.18632/oncotarget.4661.

21. Işın M, Uysaler E, Özgür E, Köseoğlu H, Şanlı Ö, Yücel ÖB, Gezer U, Dalay N. Exosomal lncRNA-p21 levels may help to distinguish prostate cancer from benign disease. Front Genet. 2015; 6: 168.

22. Yoon JH, Abdelmohsen K, Srikantan S, Yang X, Martindale JL, De S, Huarte M, Zhan M, Becker KG, Gorospe M. LincRNA-p21 suppresses target mRNA translation. Mol Cell. 2012; 47: 648-655.

23. Kim KH, Seol HJ, Kim EH, Rheey J, Jin HJ, Lee Y, Joo KM, Lee J, Nam DH. Wnt/ $\beta$-catenin signaling is a key downstream mediator of MET signaling in glioblastoma stem cells. Neuro Oncol. 2013; 15: 161-171.

24. Zhang K, Zhu S, Liu Y, Dong X, Shi Z, Zhang A, Liu C, Chen L, Wei J, Pu P, Zhang J, Jiang T, Han L, et al. ICAT inhibits glioblastoma cell proliferation by suppressing Wnt/ $\beta$-catenin activity. Cancer Lett. 2015; 357: 404-411. 
25. Chen X, Hu W, Xie B, Gao H, Xu C, Chen J. Downregulation of SCAI enhances glioma cell invasion and stem cell like phenotype by activating Wnt/ $\beta$-catenin signaling. Biochem Biophys Res Commun. 2014; 448: 206-211.

26. Kang MJ, Ryu BK, Lee MG, Han J, Lee JH, Ha TK, Byun DS, Chae KS, Lee BH, Chun HS, Lee KY, Kim HJ, Chi SG. NF-kappaB activates transcription of the RNA-binding factor $\mathrm{HuR}$, via PI3K-AKT signaling, to promote gastric tumorigenesis. Gastroenterology. 2008; 135: 2030-2042.

27. Chou SD, Murshid A, Eguchi T, Gong J, Calderwood SK. HSF 1 regulation of $\beta$-catenin in mammary cancer cells through control of HuR/elavL1 expression. Oncogene. 2015; 34: 2178-2188.

28. To KK, Leung WW, Ng SS. Exploiting a novel miR$519 \mathrm{c}-\mathrm{HuR}-\mathrm{ABCG} 2$ regulatory pathway to overcome chemoresistance in colorectal cancer. Exp Cell Res. 2015; 338: 222-231.

29. Roff AN, Craig TJ, August A, Stellato C, Ishmael FT. MicroRNA-570-3p regulates HuR and cytokine expression in airway epithelial cells. Am J Clin Exp Immunol. 2014; 3: $68-83$.

30. Guo J, Li M, Meng X, Sui J, Dou L, Tang W, Huang X, Man Y, Wang S, Li J. MiR-291b-3p induces apoptosis in liver cell line NCTC1469 by reducing the level of RNAbinding protein HuR. Cell Physiol Biochem. 2014; 33: 810-822.

31. Li JH, Liu S, Zhou H, Qu LH, Yang JH. starBase v2.0: decoding miRNA-ceRNA, miRNA-ncRNA and proteinRNA interaction networks from large-scale CLIP-Seq data. Nucleic Acids Res. 2014; 42: D92-D97.

32. Yang JH, Li JH, Shao P, Zhou H, Chen YQ, Qu LH. starBase: a database for exploring microRNA-mRNA interaction maps from Argonaute CLIP-Seq and Degradome-Seq data. Nucleic Acids Res. 2011; 39: D202-D209.

33. Yang W, Shen Y, Wei J, Liu F. MicroRNA-153/Nrf-2/ GPx1 pathway regulates radiosensitivity and stemness of glioma stem cells via reactive oxygen species. Oncotarget. 2015; 6: 22006-22027. doi: 10.18632/ oncotarget.4292.

34. Dou C, Wang Y, Li C, Liu Z, Jia Y, Li Q, Yang W, Yao Y, Liu Q, Tu K. MicroRNA-212 suppresses tumor growth of human hepatocellular carcinoma by targeting FOXA1. Oncotarget. 2015; 6: 13216-13228. doi: 10.18632/ oncotarget.3916.

35. Gordan JD, Bertovrt JA, Hu CJ, Diehl JA, Simon MC. HIF-2 $\alpha$ promotes hypoxic cell proliferation by enhancing c-Myc transcriptional activity. Cancer Cell. 2007; 11: 335-347.

36. Nilsson JA, Maclean KH, Keller UB, Pendeville H, Baudino TA, Cleveland JL. Mnt Loss Triggers Myc Transcription Targets, Proliferation, Apoptosis, and Transformation. Mol Cell Biol. 2004; 24: 1560-1569.
37. Murphy MJ, Wilson A, Trumpp A. More than just proliferation: Myc function in stem cells. Trends Cell Biol. 2005; 15: 128-137.

38. Hsu SD, Chu CH, Tsou AP, Chen SJ, Chen HC, Hsu PW, Wong YH, Chen YH, Chen GH, Huang HD. MiRNAMap 2.0: genomic maps of microRNAs in metazoan genomes. Nucleic Acids Res. 2008; 36: D165-D169.

39. Chou CK, Chen RF, Chou FF, Chang HW, Chen YJ, Lee YF, Yang KD, Cheng JT, Huang CC, Liu RT. MiR-146b is highly expressed in adult papillary thyroid carcinomas with high risk features including extrathyroidal invasion and the BRAF (V600E) mutation. Thyroid. 2010; 20: 489-494.

40. Patnaik SK, Kannisto E, Mallick R, Yendamuri S. Overexpression of the lung cancer-prognostic miR-146b microRNAs has a minimal and negative effect on the malignant phenotype of A549 lung cancer cells. PLoS One. 2011; 6: e22379.

41. Li Y, Wang Y, Yu L, Sun C, Cheng D, Yu S, Wang Q, Yan Y, Kang C, Jin S, An T, Shi C, Xu J, et al. miR146b-5p inhibits glioma migration and invasion by targeting MMP16. Cancer Letters. 2013; 339: 260-269.

42. Liu J, Xu J, Li H, Sun C, Yu L, Li Y, Shi C, Zhou X, Bian $\mathrm{X}$, Ping Y, Wen Y, Zhao S, Xu H, et al. miR-146b-5p functions as a tumor suppressor by targeting TRAF6 and predicts the prognosis of human gliomas. Oncotarget. 2015; 6: 29129-29142. doi: 10.18632/oncotarget.4895.

43. LB Nabors, GY Gillespie, L Harkins, PH King. HuR, a RNA Stability Factor, Is Expressed in Malignant Brain Tumors and Binds to Adenine- and Uridine-rich Elements within the 3' Untranslated Regions of Cytokine and Angiogenic Factor mRNAs. Cancer Res. 2001; 61: 2154-2161.

44. Abdelmohsen K, Gorospe M. Posttranscriptional regulation of cancer traits by HuR. Wiley Interdiscip Rev RNA. 2010; 1: 214-229.

45. Lafon I, Carballes F, Brewer G, Poiret M, Morello D. Developmental expression of AUF1 and HuR, two c-myc mRNA binding proteins. Oncogene. 1998; 16: 3413-3421.

46. Kim HH, Kuwano Y, Srikantan S, Lee EK, Martindale JL, Gorospe1 M. HuR recruits let-7/RISC to repress c-Myc expression. Genes Dev. 2009; 23: 1743-1748.

47. Sun T, Zhou Y, Xie X, Chen G, Li B, Wei Y, Chen J, Huang Q, Du Z. Selective uptake of boronophenylalanine by glioma stem/progenitor cells. Appl Radiat Isot. 2012; 70: 1512-1518.

48. Huang Q, Zhang QB, Dong J, Wu YY, Shen YT, Zhao YD, Zhu YD, Diao Y, Wang AD, Lan Q. Glioma stem cells are more aggressive in recurrent tumors with malignant progression than in the primary tumor, and both can be maintained long-term in vitro. BMC Cancer. 2008; 8: 304.

49. Bolognani F, Gallani AI, Sokol L, Baskin DS, MeisnerKober N. mRNA stability alterations mediated by HuR are necessary to sustain the fast growth of glioma cells. J Neurooncol. 2012; 106: 531-542. 